\title{
An Observational Estimate of the Direct Response of the Cold-Season Atmospheric Circulation to the Arctic Sea Ice Loss $\mathscr{O}$
}

\author{
Amélie Simon, Claude Frankignoul, and Guillaume Gastineau \\ Sorbonne Université, IRD/MNHN/CNRS, LOCEAN, Paris, France \\ YOUNG-OH KWON \\ Woods Hole Oceanographic Institution, Woods Hole, Massachusetts
}

(Manuscript received 13 September 2019, in final form 7 January 2020)

\begin{abstract}
The direct response of the cold-season atmospheric circulation to the Arctic sea ice loss is estimated from observed sea ice concentration (SIC) and an atmospheric reanalysis, assuming that the atmospheric response to the long-term sea ice loss is the same as that to interannual pan-Arctic SIC fluctuations with identical spatial patterns. No large-scale relationship with previous interannual SIC fluctuations is found in October and November, but a negative North Atlantic Oscillation (NAO)/Arctic Oscillation follows the pan-Arctic SIC fluctuations from December to March. The signal is field significant in the stratosphere in December, and in the troposphere and tropopause thereafter. However, multiple regressions indicate that the stratospheric December signal is largely due to concomitant Siberian snow-cover anomalies. On the other hand, the tropospheric January-March NAO signals can be unambiguously attributed to SIC variability, with an Iceland high approaching $45 \mathrm{~m}$ at $500 \mathrm{hPa}$, a $2^{\circ} \mathrm{C}$ surface air warming in northeastern Canada, and a modulation of blocking activity in the North Atlantic sector. In March, a $1^{\circ} \mathrm{C}$ northern Europe cooling is also attributed to SIC. An SIC impact on the warm Arctic-cold Eurasia pattern is only found in February in relation to January SIC. Extrapolating the most robust results suggests that, in the absence of other forcings, the SIC loss between 1979 and 2016 would have induced a $2^{\circ}-3^{\circ} \mathrm{C} \mathrm{decade}^{-1}$ winter warming in northeastern North America and a $40-60 \mathrm{~m} \mathrm{decade}^{-1}$ increase in the height of the Iceland high, if linearity and perpetual winter conditions could be assumed.
\end{abstract}

\section{Introduction}

The Arctic Ocean has shown remarkable changes in recent decades, as the surface air temperature has risen 2 times faster than the global average, and the Arctic sea ice extent and thickness have strongly declined (RichterMenge and Mathis 2017). Although internally generated variability may have substantially contributed to the Arctic sea ice loss (Screen et al. 2014), these trends are expected to continue in response to increasing greenhouse gas concentration, eventually yielding a summer ice-free Arctic (e.g., Liu et al. 2013). The Arctic sea ice

Supplemental information related to this paper is available at the Journals Online website: https://doi.org/10.1175/JCLI-D-190687.s1.

Corresponding author: Claude Frankignoul, cf@locean-ipsl.upmc.fr decline has strong local impacts on the atmosphere, but its influence on the lower latitudes remains debated (Cohen et al. 2014; Walsh 2014; Barnes and Screen 2015; Blackport et al. 2019) because of their large internal variability and the other factors that influence it, such as greenhouse gases and aerosols.

Because forcing can be specified, simulations with atmospheric general circulation models (AGCMs) have been used to investigate the impact of the sea ice loss. However, the signal-to-noise ratio is small, requiring large ensembles to estimate it (Screen et al. 2014). Further, models have mean state biases that may affect the simulated response (Smith et al. 2017). While the near-surface warming and surface flux response to the sea ice retreat are well established (e.g., Kim et al. 2014), the response is less robust for midlatitude linkages. For instance, Perlwitz et al. (2015) found in two AGCMs that the large-scale response to the sea ice decline was small in October-December. Screen et al. (2014) also 
found little response in autumn, but in their study one model (among two) simulated a winter response projecting onto the positive phase of the North Atlantic Oscillation (NAO)/Arctic Oscillation (AO). Besides, a negative NAO/ AO-like response via a stratospheric pathway was found in some studies (Peings and Magnusdottir 2014; Kim et al. 2014; Sun et al. 2015; Nakamura et al. 2015; Zhang et al. 2018), while a NAO response via a tropospheric pathway whose polarity depends on sea ice loss magnitude was found by Petoukhov and Semenov (2010), and no significant response was reported in McCusker et al. (2016) and Peings (2019).

Coupled climate models show a broadly consistent negative AO-like equilibrium response to sea ice loss (e.g., Deser et al. 2015; Blackport and Kushner 2017; Smith et al. 2017; Screen et al. 2018), yet McCusker et al. (2017) found no significant impact of recent sea ice changes on the Eurasian temperature, unlike that expected from an AO response. The retreat of the Arctic sea ice edge predicted for the end of the twenty-first century should warm and moisten the high-latitude atmosphere and decrease the equator-to-pole lower-tropospheric temperature gradient, weakening and shifting equatorward the westerlies (e.g., Deser et al. 2015; Ronalds et al. 2018). Conversely, the warming in the tropical mid- and high troposphere associated with a decline of the moist adiabatic lapse rate is projected to increase the equator-to-pole temperature gradient as the climate warms (Bony et al. 2006), leading to opposing influences of sea ice and greenhouse gases on the atmospheric circulation (e.g., Oudar et al. 2017; Blackport and Kushner 2017; Sun et al. 2018).

Given the short length of observations, the substantial internal variability of the atmospheric circulation, and possible nonstationarity (Kolstad and Screen 2019), the impact of the sea ice decline is difficult to estimate empirically, and causality is hard to establish. Several studies have suggested that Arctic sea ice loss and Arctic amplification increase the likelihood of persistent weather patterns and cold extremes during winter (e.g., Francis and Vavrus 2012; Vavrus et al. 2017), but the hypothesized mechanisms and the robustness of these findings have been questioned (e.g., Screen and Simmonds 2013; Wallace et al. 2014), and cause and effect were not always distinguished. In addition, the impacts of the different forcings on the cold extremes were not separated [see the review by Cohen et al. (2014); Walsh 2014]. Yet, it remains desirable to establish observational constraints on the model findings and single out the impact of sea ice loss using observations alone.

Here, we attempt to establish the atmospheric response to the long-term Arctic sea ice loss based on the premise that, in view of the short atmospheric response time to SIC fluctuations (Deser et al. 2007; Frankignoul et al. 2014), the direct impact of the slow SIC decrease should be similar, albeit with different magnitude, to that of interannual SIC fluctuations with identical panArctic spatial pattern. By direct impact we mean the atmospheric response to SIC changes with a relatively short response time (i.e., a few weeks to a couple months) as opposed to the indirect response that could be due to remote sea ice-driven changes in sea surface temperature or land surface state. A focus on the interannual SIC variability disentangles the SIC impact from the slower changes due to anthropogenic forcing. In addition, the response to interannual SIC fluctuations can be estimated with more confidence than their trend. This direct atmospheric response should be comparable to AMIP-type AGCM simulations forced by prescribed, time-varying sea ice fluctuations. It will not document the slow climate response to the sea ice loss, which involves various feedback and active coupling with the ocean and may take decades to reach quasi-equilibrium (Deser et al. 2015; Screen et al. 2018), but it should describe the atmospheric processes that initiate it.

Modeling studies indicate that the atmospheric response critically depends on the geographical location of the SIC changes, with opposing response to sea ice loss in the Atlantic and Pacific sectors (Sun et al. 2015; Kug et al. 2015; Pedersen et al. 2016; McKenna et al. 2018). As the response to pan-Arctic sea ice loss strongly differs from the cumulative effects of different regional sea ice losses (Screen 2017), we focus on the response to the interannual fluctuations of the amplitude of the pan-Arctic sea ice loss pattern in each calendar month. To distinguish between cause and effect, we use lag regression between SIC and the atmosphere, refining the analysis of Francis et al. (2009), Liu et al. (2012), Tang et al. (2013), and others, in that we consider the twodimensional pattern of sea ice loss instead of the average or sum of sea ice-covered area. In addition, we use monthly data. Our analysis differs from regressing on area-averaged SIC in limited regions such as the BarentsKara (BK) Seas (e.g., King et al. 2016; Yang et al. 2016; Zhang et al. 2018) or from maximum covariance analysis that emphasizes the SIC patterns of largest covariability with the atmosphere (Wu and Zhang 2010; Jaiser et al. 2012; Frankignoul et al. 2014; Handorf et al. 2015; GarcíaSerrano et al. 2015, and many others), which differ from the long-term sea ice loss patterns. To ensure robust results, global or field statistical significance is estimated using the false discovery rate (Wilks 2016). This more powerful test leads to substantially fewer significant changes than the local tests used in most previous studies.

Direct attribution of the lag-regression results to SIC fluctuations requires that there be no synchronous interannual forcing by remote sources, such as sea surface 
temperature (SST) and continental snow-cover anomalies, which may also influence the atmospheric circulation (e.g., Czaja and Frankignoul 2002; Handorf et al. 2015; Furtado et al. 2016; Gastineau et al. 2017). As SIC, SST, and snow cover may be affected by the same atmospheric fluctuations, and Arctic SIC changes are influenced by tropical teleconnections (e.g., Ding et al. 2014; Flournoy et al. 2016), some covariability is expected. In addition, the quasi-biennial oscillation (QBO) may modulate the relationship between the $\mathrm{NAO} / \mathrm{AO}$ and snow-cover variability (Peings et al. 2017). Hence, attribution should be based on multiple regressions.

We consider the atmospheric response to the sea ice loss during the cold season, from October to March, when the heat release by the sea ice loss into the lower atmosphere is largest and likely to have the strongest influence (Cohen et al. 2014; Taylor et al. 2018). It is also the season when the northern polar vortex develops and exhibits significant intraseasonal variability (Hardiman et al. 2010; Kidston et al. 2015). Data and methods are presented in section 2 . The response to interannual sea ice loss fluctuations is estimated in section 3, and the direct impact of the Arctic SIC loss between 1979 and 2016 in section 4. A summary and discussion follow in section 5.

\section{Data and methods}

\section{a. Observational data}

Monthly SIC based on passive microwave measurements is obtained at $25-\mathrm{km}$ resolution from the National Snow and Ice Data Center (NSIDC) from January 1979 to February 2017, using linear interpolation for December 1987 and January 1988, which have many missing days (Cavalieri et al. 1996). To reduce the spatial coverage, grid points where the SIC minimum is always $>90 \%$ or the SIC maximum $<1 \%$ in a given calendar month are omitted. SIC anomalies are obtained by subtracting their long-term monthly means. Monthly anomalies in sea level pressure (SLP), geopotential height at 500 (Z500), 200 (Z200), and $50 \mathrm{hPa}$ (Z50), surface air temperature at $2 \mathrm{~m}$ (SAT), 1000-500-hPa thickness $(\Delta Z)$, and zonal wind at 700 (U700), 300 (U300), and $50 \mathrm{hPa}$ (U50) are derived from ERA-Interim interpolated onto a $2^{\circ}$ grid (Dee et al. 2011). Storm tracks monthly anomalies are calculated from the 2.5-6-day bandpass-filtered (Blackmon 1976) Z500 standard deviation. We also consider the number of blocking days in each month in $30^{\circ}-75^{\circ} \mathrm{N}$, using ERAInterim and calculated following Scherrer et al. (2006), which is based on the reversal of the meridional gradient of the daily Z500, plus an additional criterion ensuring a westerly wind to the north of the block. Blocking days are identified when the two criteria are satisfied for 5 or more days (see Kwon et al. 2018). Monthly SST anomalies are taken from HadISST (Rayner et al. 2003). Weekly Northern Hemisphere continental snow cover is retrieved from the NOAA/Rutgers University Global Snow Laboratory (Robinson et al. 2012), then aggregated into monthly data. Following Naujokat (1986), the QBO index is defined by the zonal average in $4^{\circ} \mathrm{S}-4^{\circ} \mathrm{N}$ of the zonal wind at $30 \mathrm{hPa}$ in ERA-Interim.

\section{b. Methods}

For each calendar month, an area-weighted empirical orthogonal function (EOF) analysis of the SIC anomalies provides the dominant SIC patterns and their time evolution, the principal components (PCs). In all months of interest here (July-February), the SIC decrease from 1979 to 2016 is well represented by the first EOF and PC (PC1) (Fig. 1), while the higher PCs are dominated by interannual to multidecadal fluctuations, except in February where PC2 contributes to the SIC decrease in the Labrador Sea. As illustrated in Fig. 1, the long-term sea ice retreat can be approximated by a quadratic polynomial in the period of reliable satellite observations. Subtracting the quadratic fit yields detrended time series (hereafter $\mathrm{dPC} 1$ ) that vary primarily on interannual time scale, with some decadal and longer fluctuations also visible (hereafter interannual fluctuations). It was verified that regressing the SIC anomalies, after removing a quadratic trend, onto the dPC1s provides nearly identical SIC patterns. All dPC1s are standardized, hence the estimated atmospheric signals have a magnitude representative of typical SIC variability. Because of inherent SIC persistence, the dPC1s of successive calendar months tend to be well correlated, though less so between December and January (correlation $r=0.43$ ).

The atmospheric response to the interannual SIC fluctuations is estimated by lag regression onto the $\mathrm{dPC} 1 \mathrm{~s}$, after a quadratic trend has been removed from the atmospheric variables, assuming that it does not substantially vary during the satellite observational period. We consider SIC leading the atmosphere by $1-3$ months, consistent with the limited persistence of SIC anomalies and the typical 1-2-month atmospheric response time (Deser et al. 2007; Frankignoul et al. 2014). In-phase relations are likely dominated by the atmosphere forcing the SIC anomalies and are not given, although they also represent the fast, direct thermodynamical SAT response to SIC changes. Simultaneous regression is used to estimate the concomitant SST, QBO, and snow-cover fluctuations. The interannual SST anomalies are derived by removing the externally forced monthly SST signal given by an updated optimal perturbation filter based on linear inverse modeling [LIMopt, as recommended in Frankignoul et al. (2017)], then removing for consistency a quadratic trend (broadly similar results are obtained by 

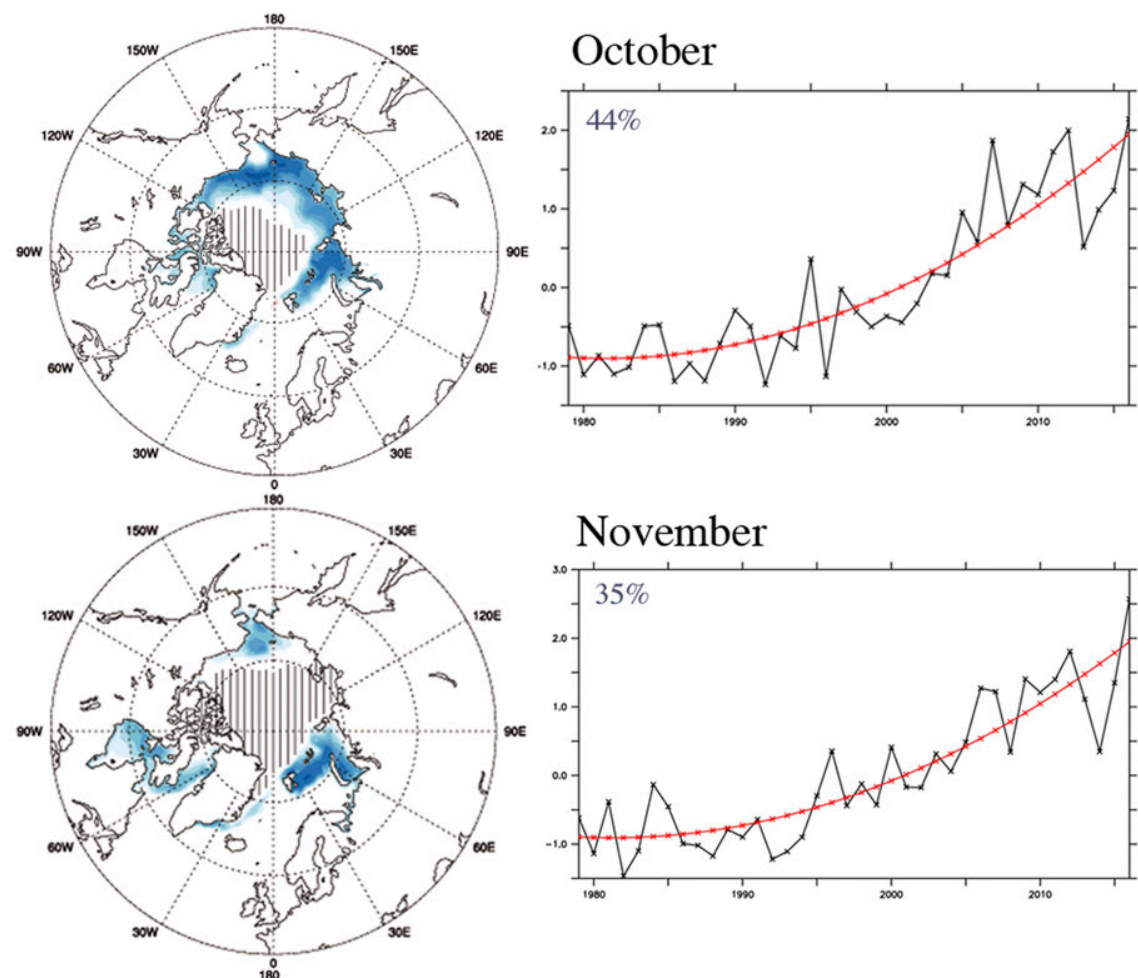

November

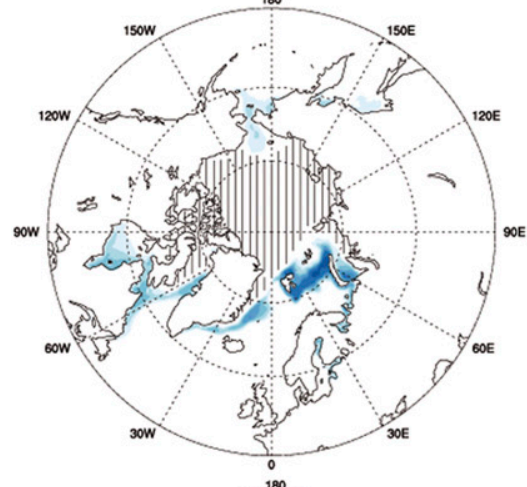

\section{December}
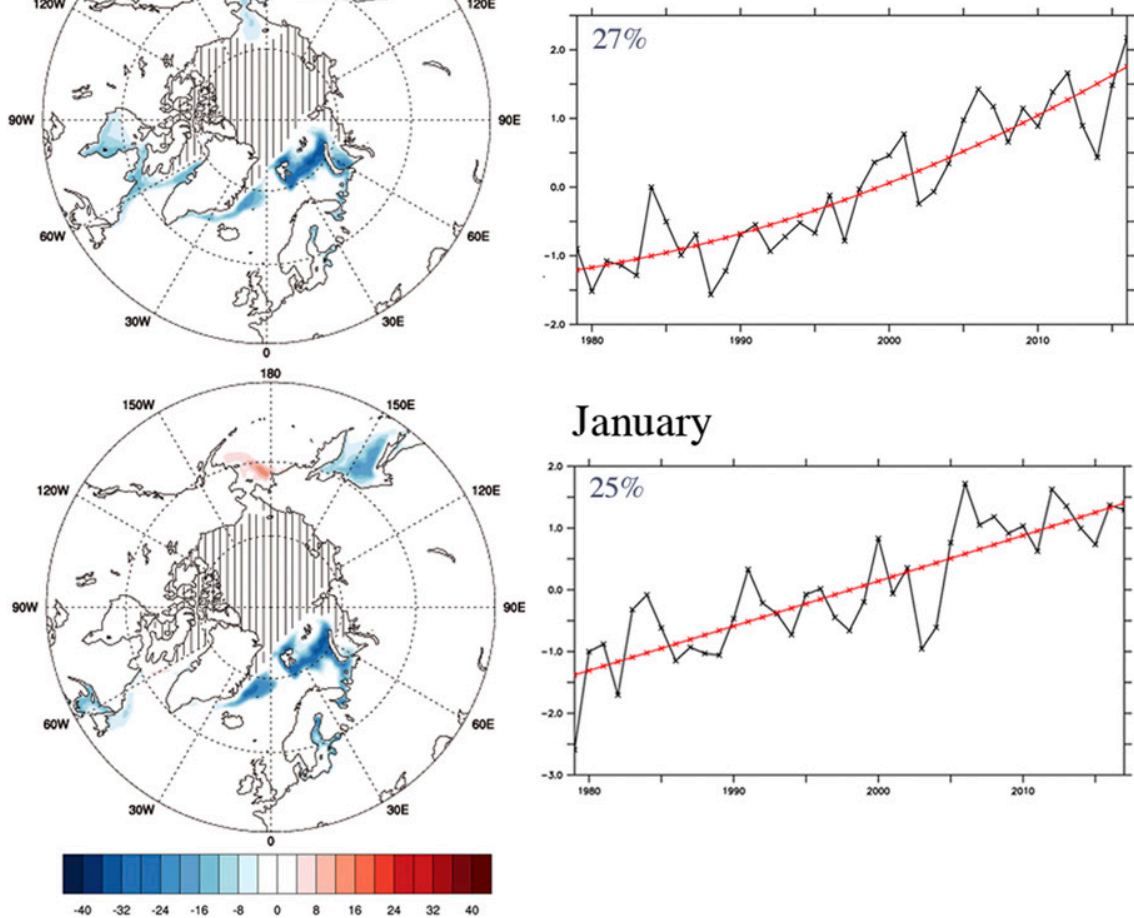

January

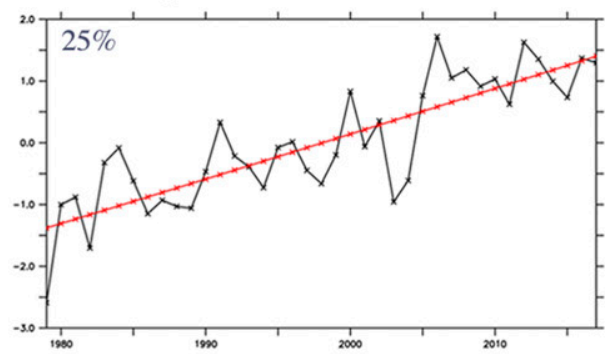

FIG. 1. (left) First EOF (\%) and (right) PC for SIC during (top to bottom) October, November, December, and January. The percentage of explained variance is indicated. The red lines show the quadratic polynomial fit. Hatching indicates the areas where the minimum SIC is always larger than $90 \%$. 
only removing a quadratic trend). The interannual snow-cover and QBO fluctuations are obtained by removing quadratic trends, lacking more refined estimates of the externally forced signals, even though it might not be optimal in all areas.

As there is little year-to-year correlation in the detrended atmospheric fields, statistical significance of the lag regressions is estimated at the $10 \%$ level using a two-sided Student's $t$ test with $n-2$ degrees of freedom, where $n$ is the number of years in the regressions. The $t$ test is also used for the multiple regressions. It was verified that taking atmospheric persistence into account had a negligible impact on statistical significance, even in the stratosphere. Persistence is taken into account when estimating the degrees of freedom of synchronous relations between the dPC1s and SST and snow-cover anomalies, as in Bretherton et al. (1999). As global or field significance requires that the null hypothesis be rejected at more than $10 \%$ of the grid points (von Storch and Zwiers 2001), field significance is assessed by controlling the false discovery rate (FDR; Wilks 2016), a more powerful statistical test. For the atmospheric variables, we a priori focus on the northern extratropical latitudes and use a FDR level of $10 \%$ between $25^{\circ}$ and $85^{\circ} \mathrm{N}$ (hereafter $\mathrm{NH}$ ). This excludes the tropical latitudes that are strongly influenced by equatorial SST variability, which would lead to a very small signal-to-noise ratio, and the polar cap where grid spacing is very small with a $2^{\circ}$ grid. The Southern Hemisphere is not considered, as we do not expect any rapid, direct impact of Arctic sea ice loss. We also consider the smaller $25^{\circ}-70^{\circ} \mathrm{N}, 130^{\circ} \mathrm{W}-50^{\circ} \mathrm{E}$ domain, which includes most of North America and the Euro-Atlantic sector (hereafter NA-EA), thus documenting the important anomalies at a more regional scale. The FDR procedure is also applied to estimate the field significance of concomitant SST anomalies in the tropics $\left(20^{\circ} \mathrm{S}-20^{\circ} \mathrm{N}\right)$, near the equator $\left(10^{\circ} \mathrm{S}-10^{\circ} \mathrm{N}\right)$, and in extratropical latitudes north of $20^{\circ} \mathrm{N}$. For snow-cover anomalies, the FDR procedure is applied where the climatological snow cover is not larger than $98 \%$ or smaller than $2 \%$, excluding the grid points where there is no snow for at least 12 consecutive months. This is separately done for the Northern Hemisphere and the Eurasian continent $\left(0^{\circ}-180^{\circ} \mathrm{E}\right)$. Last, the robustness of the multiple regressions was assessed by separately considering the two (short) halves of the records.

\section{Cold-season atmospheric response to interannual sea ice loss fluctuations}

\section{a. Autumn}

Lag regressions were computed for October and November on SIC leading by 1-3 months, thus regressing autumn atmospheric variables onto preceding months' interannual SIC fluctuations, with $\mathrm{dPC} 1$ taken from July to October, depending on the lag. Although $10 \%$ local significance is found in a few areas, none of the tropospheric or stratospheric regressions is field significant in either month. Field significance is only found in few areas for near-surface temperature (SAT) in October, but it is lost in a bivariate regression that includes the concomitant snow-cover decrease in northeastern Asia (not shown). Hence, the large-scale atmospheric impact of the SIC loss is negligible in autumn.

\section{b. Early winter (December)}

The sea ice loss pattern in November displays a substantial SIC decrease in the BK Seas and smaller reduction in the Chukchi Sea, the Labrador Sea, and Hudson Bay (Fig. 1). In December, as illustrated for Z50, Z500, and SLP (Fig. 2, left), the atmospheric signal regressed onto November dPC1 (lag 1) is equivalent barotropic, broadly resembling a negative phase of the $\mathrm{NAO}(\mathrm{NAO}-)$. However, there is only field significance in the stratosphere (Z50 and U50), where the polar vortex weakens, near the tropopause (Z200), and in the upper troposphere (U300). Only local significance is found below. The strong stratospheric signal and weak lower-tropospheric anomalies in December would be consistent with a signal originating in the stratosphere, as there is less downward wave or zonal-mean coupling between stratosphere and troposphere in NovemberDecember (Shaw et al. 2010), and descending into the troposphere in January. However, before suggesting that the SIC influence originates in the stratosphere, it must be verified that the signals are not due to other synchronous forcings.

To establish if there is concomitant boundary forcing, the November SST and snow-cover anomalies are regressed onto November dPC1. There is a tropical Pacific cooling that resembles La Niña, a weaker cooling in the western Indian Ocean, the eastern North Pacific, and the subtropical North Atlantic, and warming in the equatorial Atlantic, the eastern North Atlantic, and the western Pacific (Fig. 3, top). Only the eastern Atlantic SST anomalies are field significant, but all equatorial anomalies, albeit very similar, become field significant if the interannual SST anomalies are defined by only removing quadratic trends without first removing the forced signal described in section 2 . There is also a large, locally significant, concomitant snow-cover increase in southeastern Siberia and a weak decrease in northeastern America. The synchronous SST and snowcover anomalies may reflect that they were driven by atmospheric fluctuations that also affected the SIC, as is likely for the Scandinavian pattern or Ural blocking, which influence Siberian snow and BK Seas SIC (Gastineau et al. 2017; Peings 2019). Although the origin of the synchronous 

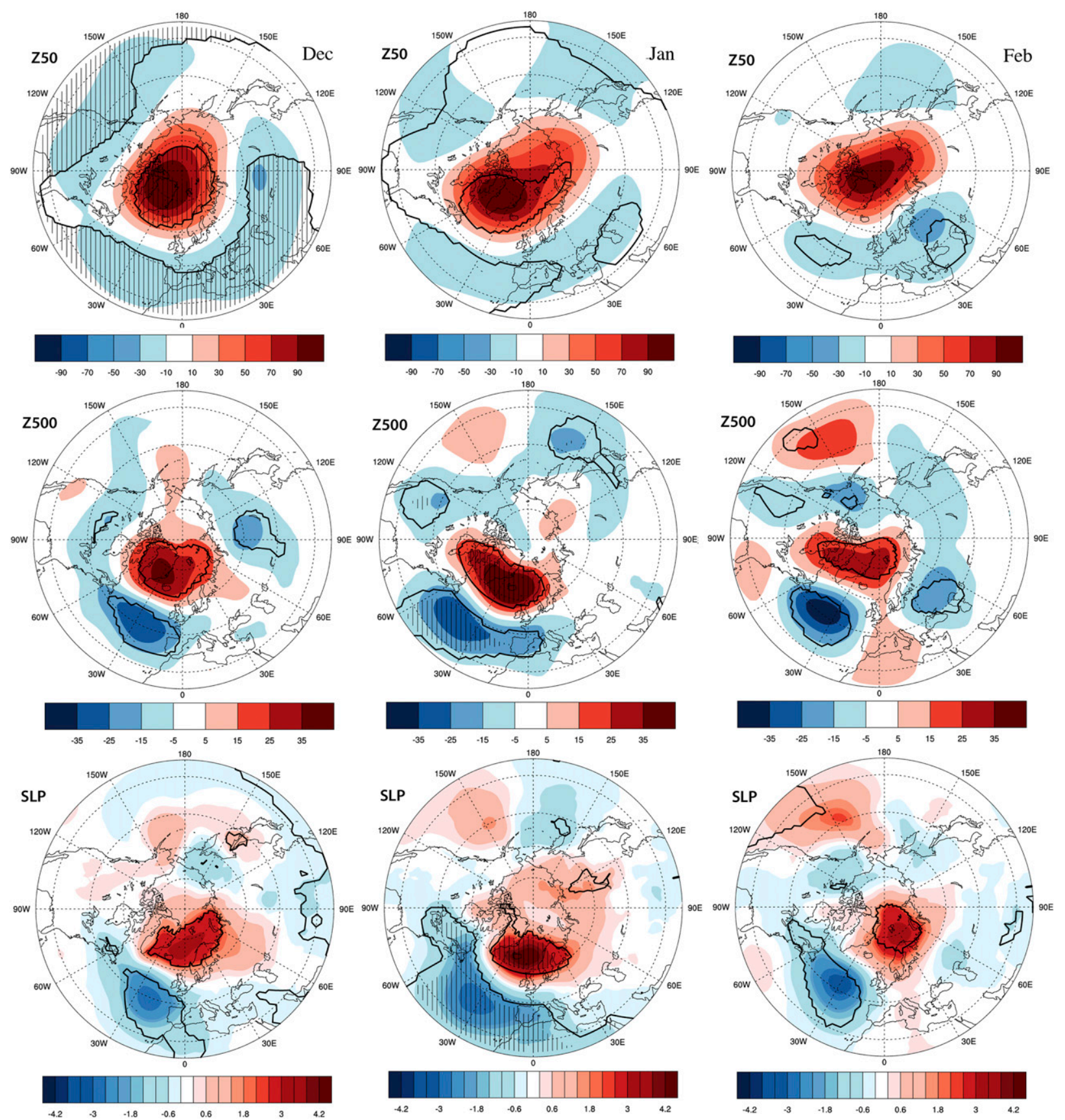

FIG. 2. Regression of the geopotential height (m) at (top) 50 and (middle) $500 \mathrm{hPa}$, and (bottom) SLP (hPa) in (left) December, (center) January, and (right) February onto November dPC1. The contours indicate 10\% significance and hatching significance based on an FDR of $10 \%$.

changes is of interest, we only focus on distinguishing their impact on the atmospheric circulation from that of the SIC fluctuations.

To perform the multiple regressions, we construct SST and snow-cover indices for the key regions in Fig. 3, taking into account their sign. Because of the limited sample (38 years), the number of regressors must be limited. Also, regressors that are too highly correlated with each other must be avoided to limit collinearity. Yet, the patterns associated with the selected indices may still have similarities, and they are often moderately correlated. However, such correlation is explicitly represented in the multiple regressions, which is one of its main advantages. A first SST index is the averaged SST 


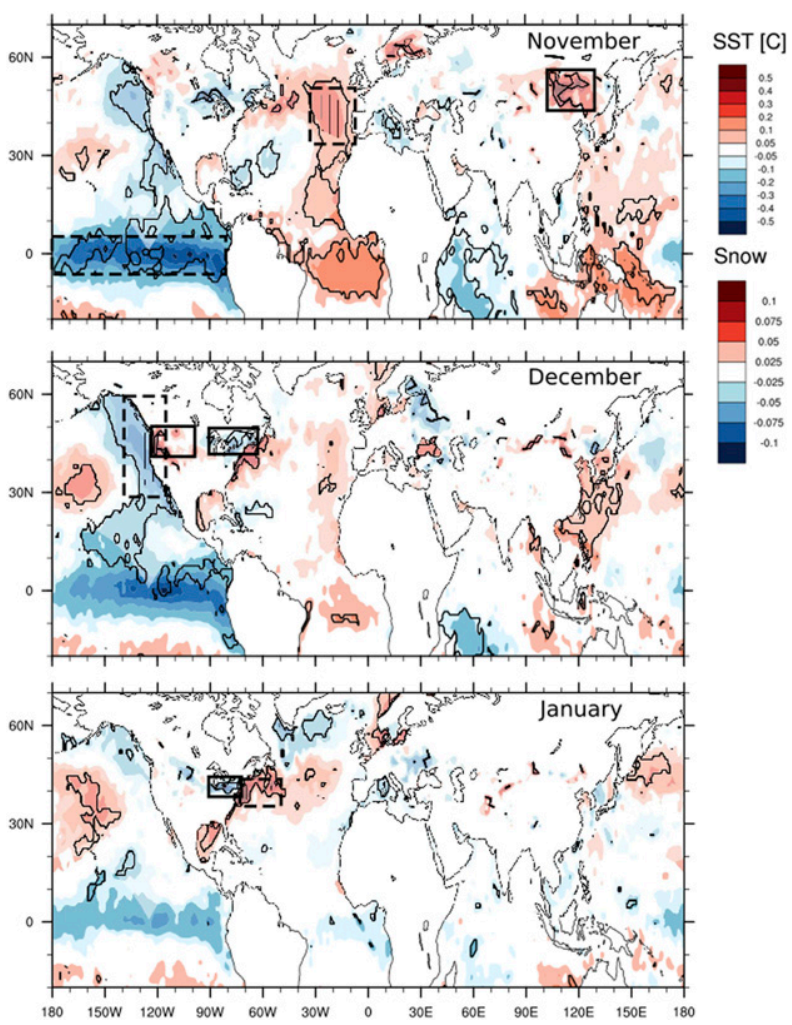

FIG. 3. Simultaneous (lag 0 ) regression of SST (over the ocean; ${ }^{\circ} \mathrm{C}$ ) and snow-cover fraction (over land) anomalies on dPC1 (the SIC index) in (top) November, (middle) December, and (bottom) January. The boxes indicate the areas used to define the indices used in the multiple regressions (see text). The contours indicate $10 \%$ significance and hatching significance based on an FDR of $10 \%$.

anomaly in the eastern equatorial Pacific $\left(5^{\circ} \mathrm{N}-5^{\circ} \mathrm{S}\right.$, $180^{\circ}-80^{\circ} \mathrm{W}$ ) with the reverse sign. It is anticorrelated with the Niño-3.4 index (thus a La Niña index). Regressions of the SST anomalies on the La Niña index indicate that it also represents very well the tropical Indian cooling (correlation coefficient reaching 0.6), and much of the tropical Atlantic and western equatorial Pacific warming in Fig. 3, so that it is representative of the concomitant SST anomalies in the whole tropics. It also represents the North Pacific anomalies and the eastern North Atlantic warming (see Fig. S1 in the online supplemental material). Nonetheless, because the latter is field significant in Fig. 3, a second SST index (correlated with the first one, $r=0.35$ ) is considered, namely the average SST anomaly in the eastern North Atlantic domain $\left(35^{\circ}-50^{\circ} \mathrm{N}, 30^{\circ}-10^{\circ} \mathrm{W}\right)$. It can be shown that this index represents very well the North Atlantic horseshoe SST anomaly, which is a main summer and autumn SST mode. For snow cover, we consider the area-averaged snow-cover anomaly in southeastern Siberia $\left(45^{\circ}-55^{\circ} \mathrm{N}, 105^{\circ}-130^{\circ} \mathrm{E}\right)$, which is also correlated to a small snow-cover decrease in northeastern North America, so that an additional snow-cover index is not needed. ${ }^{1}$ Gastineau et al. (2017) found that southeastern Siberian snow-cover anomalies were preceded by a strong anticyclone over the northern coast of Siberia and a smaller one over northeastern United States (their Fig. 10a), which might explain the opposite polarity of these snow cover anomalies. The three indices are standardized and combined with $\mathrm{dPC} 1$ to form a set of four regressors. The multicollinearity is moderate, with variance inflation factors (VIFs; Kendall 1946) $\leq 2.4$. The VIF is the factor by which the variance of a univariate regression coefficient is increased by considering the other regressors. Judge et al. (1988) state that only VIFs larger than 5, thus much larger than in the present study, are signs of severe multicollinearity and would lead to highly variable parameter estimators. Although local significance is found in a few small domains in the lag regressions on the eastern North Atlantic SST index, the regressed signals are small and none of them is field significant for any variable and lag (not shown), even though the North Atlantic SST anomaly is field significant in Fig. 3 (perhaps because both SIC and SST were affected by the same atmospheric fluctuations). Hence, our multiple regression model is unnecessarily complex. Without further screening, we omit the North Atlantic index, which substantially reduces the multicollinearity (VIF $\leq 1.5)$. The regressed signals remain very similar, but statistical significance generally increases for the regressions on the SIC index and, to a lesser extent, snow cover, while the regressions on the eastern equatorial Pacific SST index are unaltered. We only focus on the results of the model with three regressors. Although there is a weak synchronous anticorrelation $(-0.26)$ between November $\mathrm{dPC} 1$ and the QBO, adding the QBO index as an additional regressor in the multiple regressions has a negligible influence on the regression coefficients of the original three regressors. This holds for all the multiple regressions discussed below, suggesting no obvious interference between the sea ice loss and the QBO.

Interestingly, the multiple regressions (Fig. 4, top) indicate that the field significant stratospheric signal in December (Fig. 2, top left) is due to the Siberian snowcover increase, while the SST and SIC contributions are small and not even locally significant over the polar region. Near the tropopause (Z200), the only field significant signal is the Aleutian low strengthening linked to

\footnotetext{
${ }^{1}$ Adding a snow index for the region $38^{\circ}-43^{\circ} \mathrm{N}, 60^{\circ}-90^{\circ} \mathrm{W}$ increases the colinearity but only slightly affects the regression on the SIC index.
} 

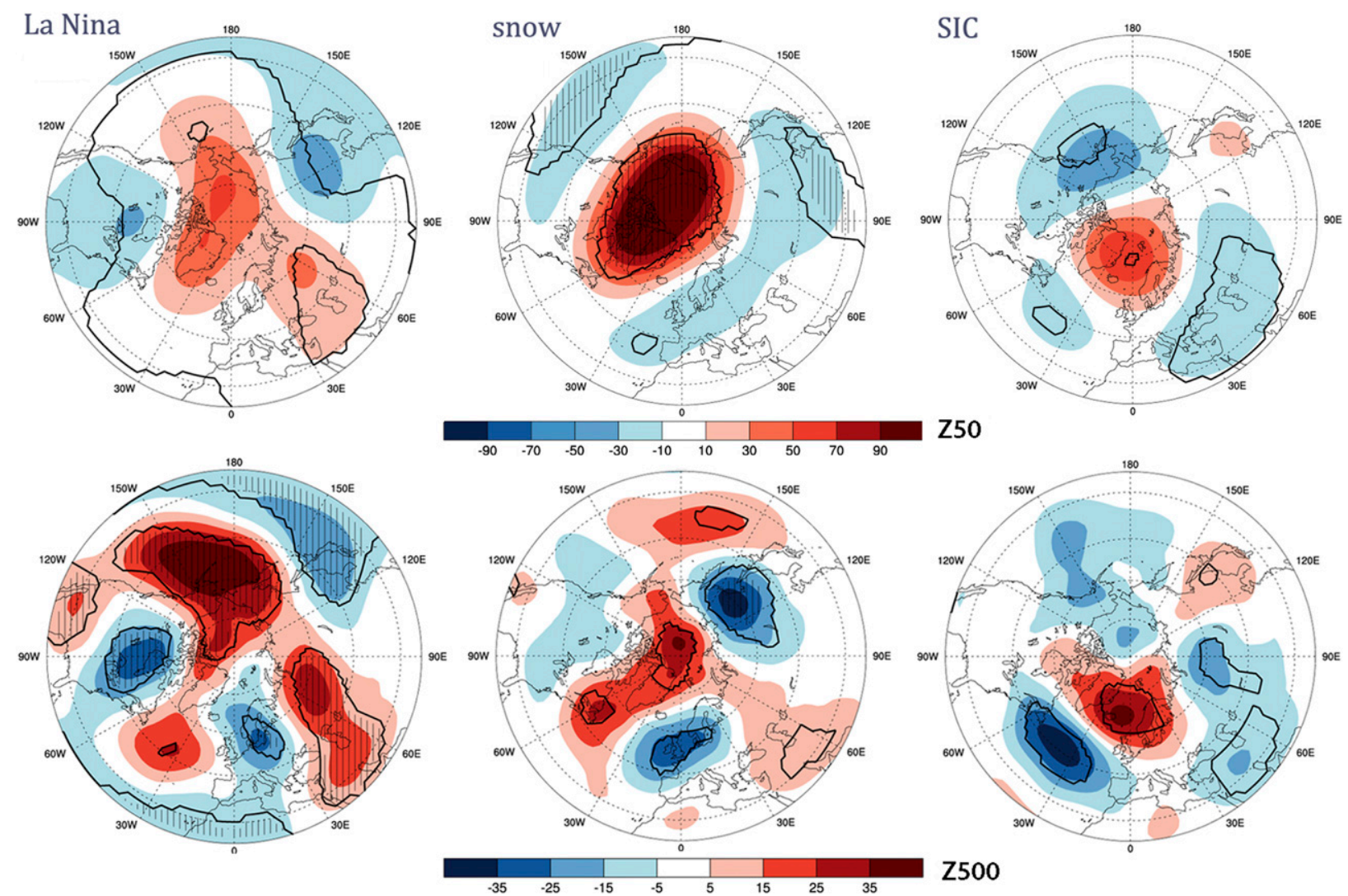

FIG. 4. Multiple regression of (top) Z50 (m) and (bottom) Z500 (m) in December on (left) the La Niña SST index, (center) Siberian snow-cover, and (right) SIC indices in November. The contours indicate $10 \%$ significance and hatching significance based on an FDR of $10 \%$.

La Niña (not shown). However, a locally significant $\mathrm{NAO}-$ is associated with SIC. In the troposphere (Fig. 4, bottom), field significance is again found for the regressions on the La Niña index, which resemble the December regression on the Niño-3.4 index in King et al. (2018, their Fig. 1) with the reverse sign, and for some regressions on the snow index. No field significance is found for the regressions on APC1 (the SIC index), even in the NA-EA domain, but the NAO- signal is locally significant. However, it is field significant in the first half of the record, but barely seen in the second half (not shown). Hence, the SIC fluctuations seem to drive a tropospheric NAO - signal in December that is too weak to reach field significance over the whole record.

\section{c. Winter}

In January, a NAO - signal is also found in the regression on the November SIC index at lag 2 (Fig. 2, middle). It is stronger than in December and field significant near the tropopause (Z200) and in the whole troposphere, with a high approaching $45 \pm 13 \mathrm{~m}$ at $500 \mathrm{hPa}$ (uncertainty estimated by the standard error) and $4 \pm 1.2 \mathrm{hPa}$ at sea level around Iceland, and a corresponding low $(\sim 30 \pm 11 \mathrm{~m}$ and $2.5 \pm 1 \mathrm{hPa})$ in the subtropics. There is also a smaller, field significant SLP decrease over northeastern Canada. Consistent with the changes illustrated in Fig. 2, the westerlies shift southeastward in the North Atlantic sector, with zonal wind anomalies approaching $-5 \pm 1.5 \mathrm{~m} \mathrm{~s}^{-1}$ at $300 \mathrm{hPa}(-3 \pm$ $0.8 \mathrm{~m} \mathrm{~s}^{-1}$ at $700 \mathrm{hPa}$ ) near $50^{\circ} \mathrm{N}$ and a smaller zonal wind increase around $32^{\circ} \mathrm{N}$. In the stratosphere, the polar vortex anomalies are similar to those in December, but without field significance. The signals are also seen in February at lag 3 (Fig. 2, right), but they are slightly weaker and without field significance, even in the troposphere. Composites indicate no significant asymmetry in the link to positive or negative SIC changes (not shown).

The multiple regressions are illustrated for SLP (Fig. 5). They confirm that the strong tropospheric NAO- signal and the small SLP decrease over northeastern Canada in January are linked to the reduced November SIC. The regressions on $\mathrm{dPC} 1$ are mostly field significant in the troposphere and of comparable amplitude to those in Fig. 2. The regressions are small in the second half of the period, but again stronger during the first half of the period (not shown). Note that the weakening of the 

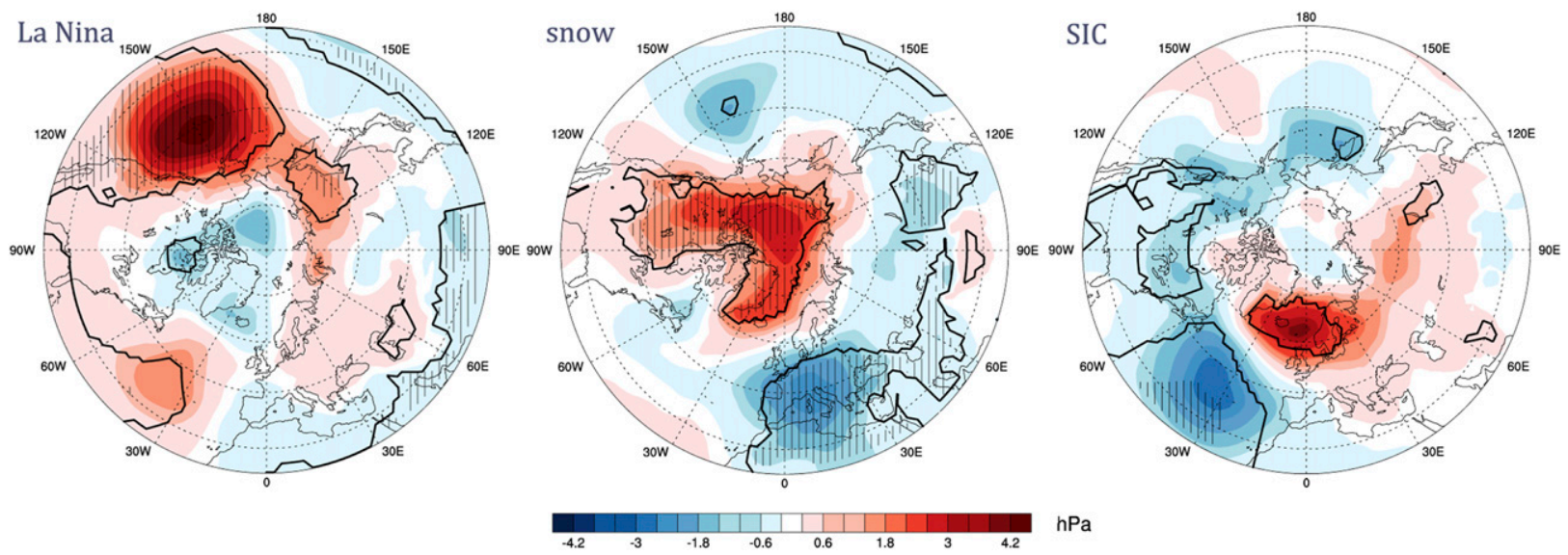

FIG. 5. Multiple regression of SLP (hPa) in January on the (left) La Niña, (center) Siberian snow-cover, and (right) SIC indices in November. The contours indicate $10 \%$ significance and hatching significance based on an FDR of $10 \%$.

Icelandic low and the SLP low over northeastern North America in the regression on dPC1 (Fig. 5, right) become field significant when the FDR is estimated in the NA-EA domain. Figure 5 also shows the Aleutian low teleconnection with La Niña (left) and that increased Siberian snow cover induces a SLP high above the Arctic and western North America and a low over Europe and Siberia (center), a different pattern from that linked to SIC. Figure 6 confirms that the southward shift of the upper-tropospheric jet in the North Atlantic sector is linked to the SIC fluctuations. The colder tropical Pacific has the opposite influence in the North Atlantic and a larger impact in the North Pacific, while snow cover drives no field significant U300 signal, reflecting a weak upper-tropospheric signal. Very similar results are found for U700 (not shown). In the stratosphere, there is a field significant polar vortex weakening in the regression on snow cover, but no field significant signal in the regressions on SIC (not shown). In summary, the reduced SIC in November has a negative NAO-like impact on the troposphere that reaches full amplitude in January, seemingly without involving a stratospheric pathway. The signal becomes weaker in February, at lag 3, probably because of the limited SIC persistence.

Broadly similar negative NAO-like signals are found when the atmospheric fields are regressed onto December dPC1, which reflects similar SIC fluctuations, but with a slight southward shift of the ice edge. It is well correlated with November dPC1 $(r=0.72)$. At lag 1 , in January, the amplitude is generally smaller than in Fig. 2 and there is no field significance (Fig. 7, left), but at lag 2 in February, robust field significance is found for the northern lobe of the NAO- signal in the troposphere (Fig. 7, center) and near the tropopause (Z200, not shown), with only slightly smaller amplitude than in Fig. 2 for January ( $40 \pm 14 \mathrm{~m}$ for $\mathrm{Z} 500$ and $3.5 \pm 1.5 \mathrm{hPa}$ for SLP around Iceland). There is an elongated weakening of the stratospheric polar vortex in January and February, together with a southward shift
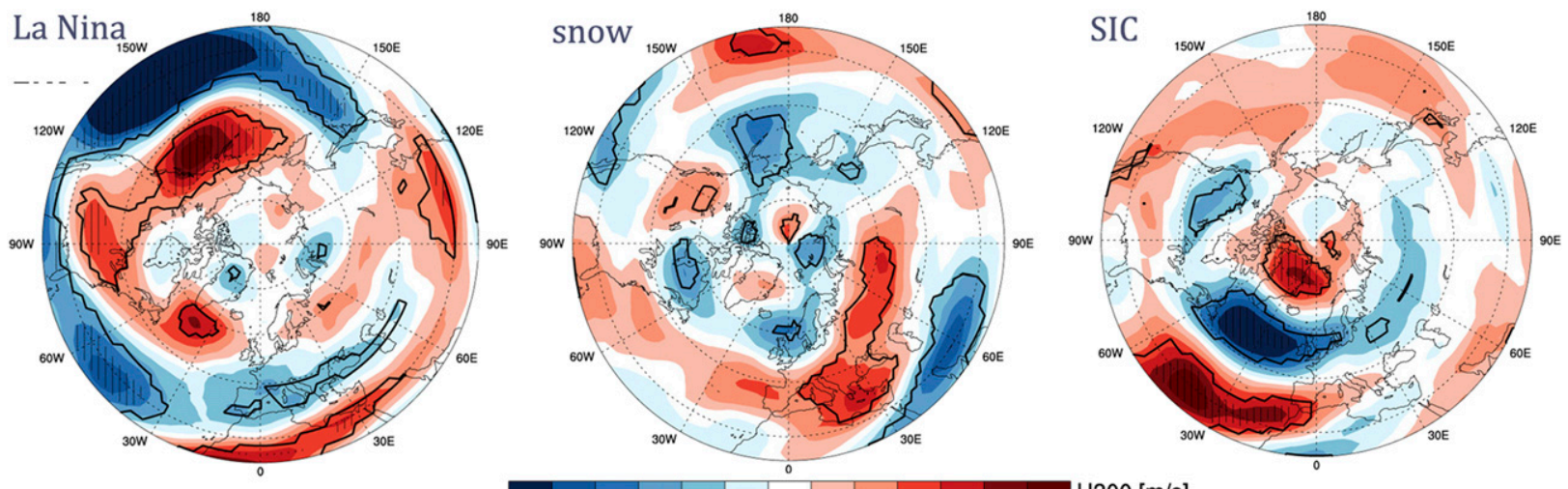

$\begin{array}{llllllllllll}-4.4 & -3.6 & -2.8 & -2 & -1.2 & -0.4 & 0.4 & 1.2 & 2 & 2.8 & 3.6 & 4.4\end{array}$

$\mathrm{U} 300[\mathrm{~m} / \mathrm{s}]$

FIG. 6. Multiple regression of U300 ( $\left.\mathrm{m} \mathrm{s}^{-1}\right)$ in January on the (left) La Niña, (center) Siberian snow-cover, and (right) SIC indices in November. The contours indicate $10 \%$ significance and hatching significance based on an FDR of $10 \%$. 

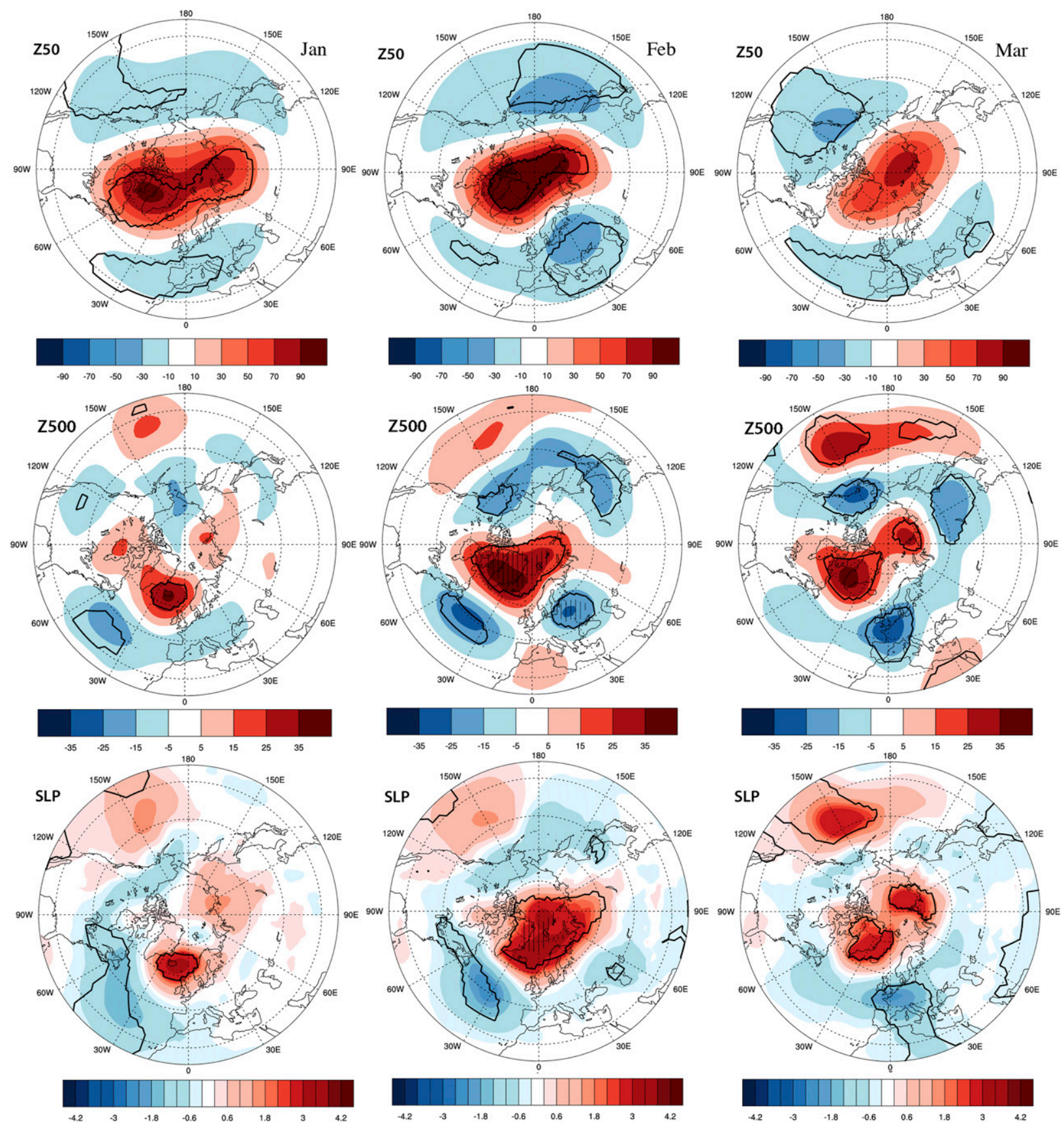

FIG. 7. Regression of the geopotential height (m) at (top) 50 and (middle) $500 \mathrm{hPa}$, and (bottom) SLP (hPa) in (left) January, (center) February, and (right) March onto December dPC1. The contours indicate $10 \%$ significance and hatching indicates FDR significance at the $10 \%$ level.

of U50 (not shown), but they are not field significant. The tropospheric NAO - signal largely persists in March (lag 3), although the amplitude and statistical significance are lower, in particular for SLP (Fig. 7, right). The NAOsignal is clearer in March in the regressions on January dPC1, but it is only field significant for SLP and Z200 in the NA-EA domain (not shown, but see Fig. 10). The March NAO - signal can be recognized in the regressions on February dPC1 at lag 1, but it is barely significant locally, and in April it disappears (not shown).

In December there are also SST and snow-cover anomalies concomitant with dPC1 (Fig. 3, middle). The most significant synchronous change is a cooling in the eastern North Pacific, well represented by minus (to reflect the negative regression coefficient) the SST average in $30^{\circ}-60^{\circ} \mathrm{N}, 115^{\circ}-140^{\circ} \mathrm{W}$. We also consider 

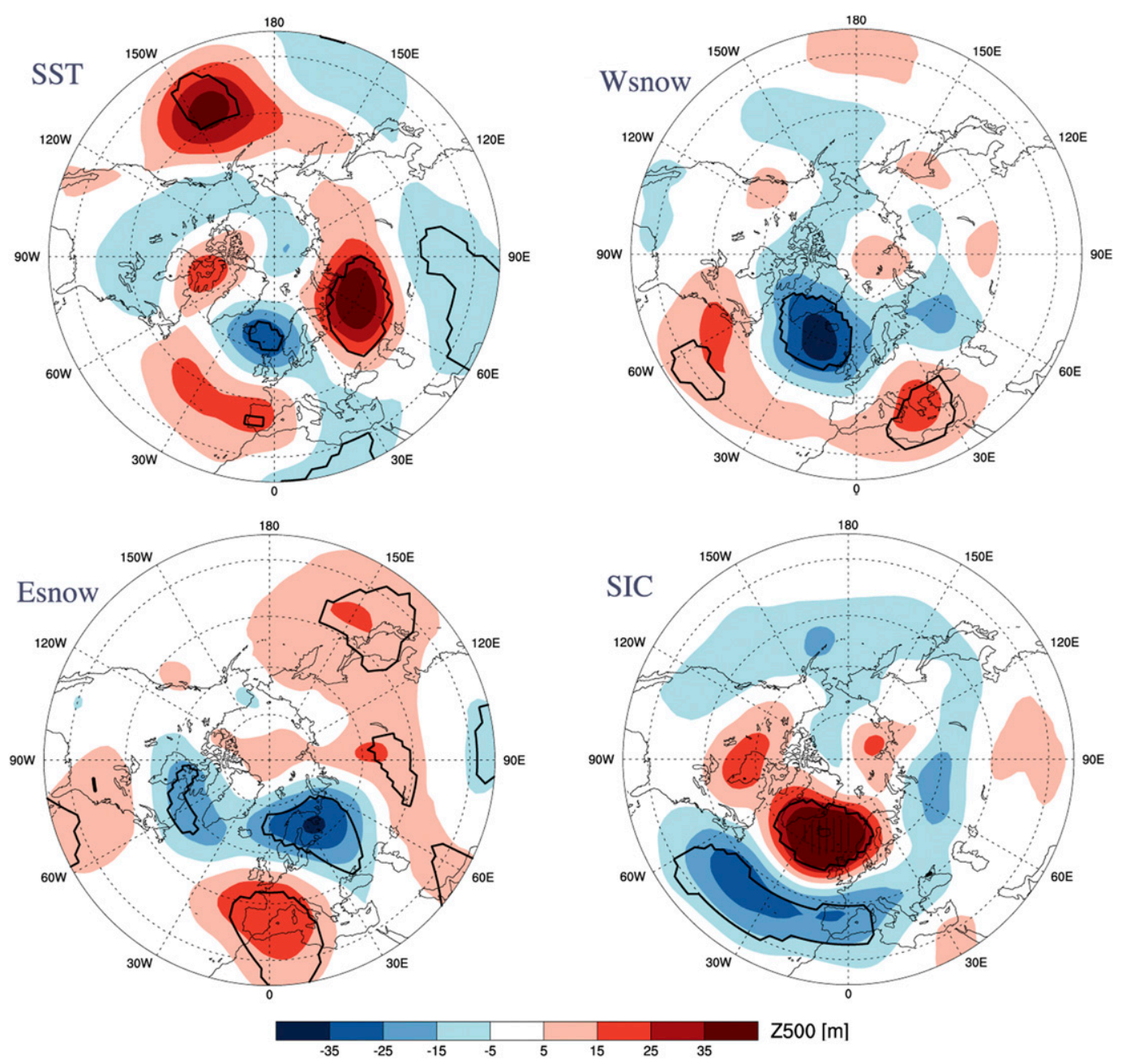

FIG. 8. Multiple regression of Z500 (m) in January onto the (top left) eastern North Pacific cooling, (top right) western North American snow-cover increase, (bottom left) the eastern North American snow-cover decrease, and (bottom right) SIC indices in December. The contours indicate 10\% significance and hatching significance based on an FDR of $10 \%$.

the averaged snow cover in western North America $\left(40^{\circ}-50^{\circ} \mathrm{N}, 125^{\circ}-110^{\circ} \mathrm{W}\right)$ and minus that in eastern North America $\left(40^{\circ}-50^{\circ} \mathrm{N}, 90^{\circ}-60^{\circ} \mathrm{W}\right)$. The latter index is highly correlated with the SST warming in the adjacent Gulf Stream region $\left(r=0.71\right.$ for SST in $\left.30^{\circ}-45^{\circ} \mathrm{N}, 80^{\circ}-50^{\circ} \mathrm{W}\right)$, so that it represents combined snow and SST forcing. To assess robustness, we have performed the multiple regression using, in addition to December dPC1, an increasing number of indices: first adding the SST index (VIFs $\leq 1.5)$, then the western North American snow index (VIFs $\leq 1.6$ ), and finally using the four indices (North Pacific SST, snow cover in western North America, snow cover in eastern North America, and December $\mathrm{dPC1}$; VIFs $\leq 1.8$ ). Interestingly, the statistical significance of the tropospheric signals linked to the SIC fluctuations is enhanced in January as regressors are added, and they more closely resemble a negative NAO, as illustrated for Z500 (Fig. 8), although adding the eastern North American snow index had no influence in this case. As before, the January NAO- signal is large in the first half of the period, but very small in the second one. In February, using multiple regressions changes little the regressions on December dPC1, but they were already highly significant. In March (lag 3), multiple regressions again enhance the statistical significance of the tropospheric link to SIC and its resemblance to NAO-, although hemispheric field significance is only found for U300 and U700. This is illustrated for U700 in the NA-EA sector (Fig. 9), where there is no field significance in the standard regression (top), limited significance with two regressors (eastern North Pacific SST, SIC; middle), barely more with three (not shown), and a strong one 

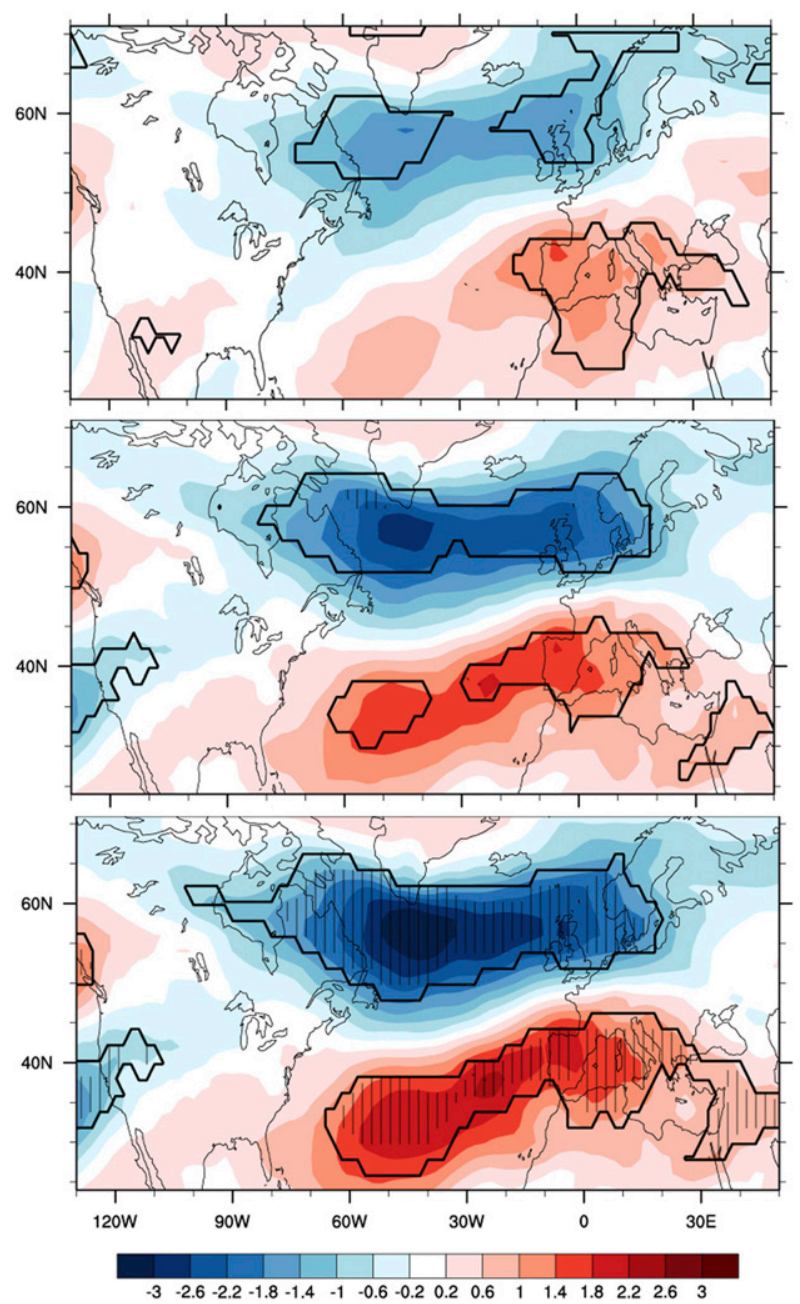

FIG. 9. Regression of U700 $\left(\mathrm{m} \mathrm{s}^{-1}\right)$ in March onto December dPC1 (top) in the standard case (SIC alone) and in multiple regression based on (middle) two indices (eastern Pacific cooling and SIC) and (bottom) four indices (eastern Pacific cooling and SIC, snow cover in western and eastern North America). The contours indicate $10 \%$ significance and hatching significance based on an FDR of $10 \%$ in the NA-EA sector.

with the four regressors (bottom). Very similar results are obtained by using the Gulf Stream SST index instead of the eastern North American snow-cover index. At the same time, a northward shift of the jet over the western North Pacific becomes clearer (not shown). In February and March, broadly similar results are found in the two halves of the period, confirming their robustness, although the February NAO-like signal is larger in the first half and the March one is larger in the second half. In the stratosphere, the January and February Z50 signals linked to SIC changes little from Fig. 7 when using multiple regression (not shown), except for the loss of North Pacific low (local) significance, and they are still not field significant. In March, even local significance is lost. In January, however, the weakening and southward shift of the zonal wind (U50) becomes field significant when the FDR is estimated in the NA-EA sector (Fig. S2). Since negligible stratospheric signals are associated with the other regressors, the stratosphere may be weakly affected in January by the December SIC fluctuations, but not later as there is no U50 field significance in February, and negligible signals in March.

In January, the only field significant SST signal concomitant with $\mathrm{dPC} 1$ is the warming off the east coast of North American (Fig. 3, bottom) represented by the averaged SST anomaly in $35^{\circ}-45^{\circ} \mathrm{N}, 75^{\circ}-50^{\circ} \mathrm{W}$. It was found that this index also reproduces much of the locally significant North Atlantic SST anomalies. There is a locally significant snow-cover decrease in northeastern United States, represented by minus the averaged snow cover in $38^{\circ}-43^{\circ} \mathrm{N}, 90^{\circ}-70^{\circ} \mathrm{W}$. When bivariate regressions (SIC and SST) are performed at lag 2, thus in March, the signals lagging dPC1 become more NAO-like and significant (not shown), but significance most strongly increases when the snow index is added in the regressions because it has an opposite impact, albeit weaker, on the atmosphere (Fig. 10). The negative NAO-like signal is equally strong in each half of the record. Hence, multiple regressions again strengthen the link with sea ice.

Consistent with the negative NAO response to the SIC fluctuations, a southward shift of the North Atlantic storm track in its southern edge is found in the multiple regressions, but it is only field significant in the NA-EA sector in January when regressed onto December dPC1 (Fig. S3). Corresponding signals are found for the number of blocking days in both standard and multiple regressions. To distinguish the SIC influence, we only show results derived from multiple regression. In January and February, the interannual SIC fluctuations precede changes in the number of blocking days that are mostly field significant in the NA-EA domain, as illustrated for the regressions on December dPC1 based on the three regressors (SST, snow cover in western North America, and SIC; Fig. 11). Blocking activity substantially decreases in the eastern subtropical North Atlantic, extending to central Europe in February, while increasing over northern Europe in January and, in February, over Greenland. The blocking patterns are consistent with the southern position of the eddy-driven jet, the associated Rossby wave breaking, and the negative NAO-like pattern (Woollings et al. 2018). Very similar patterns are obtained in January when based on November dPC1 (not shown), except that field significance is lost over northern Europe. The regression patterns in December on November dPC1 resemble those in January, but are weaker and less significant; a locally significant blocking activity increase is also found in March over southern Greenland 

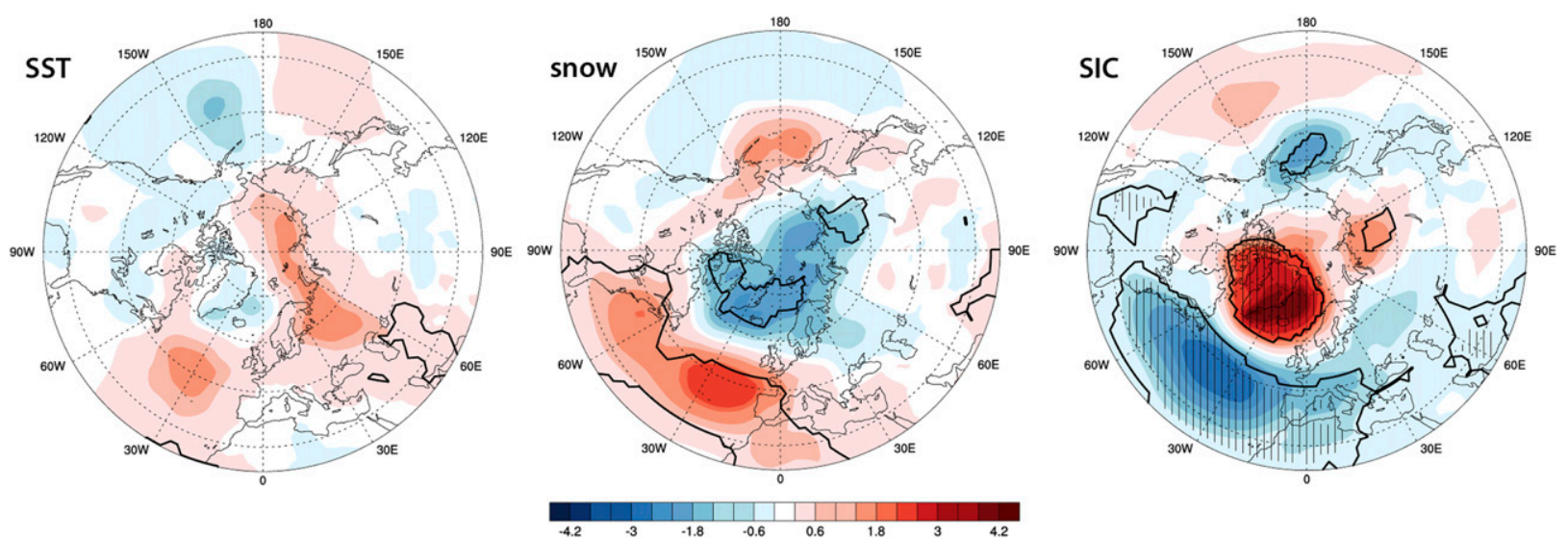

FIG. 10. Multiple regression of SLP (hPa) in March onto (left) the western North Atlantic SST, minus (center) the eastern North American snow and (right) SIC indices in January. The contours indicate 10\% significance and hatching significance based on an FDR of $10 \%$.

(not shown). The signal-to-noise ratio is thus small in early and late winter. No significant changes in the number of blocking days were seen in November and April.

In summary, a reduced pan-Arctic SIC in November, December, and January drives negative NAO-like circulation anomalies in the troposphere and near the tropopause that are best detected two month later, in January, February, and less significantly in March, respectively, and there is no evidence of a significant stratospheric pathway for the SIC impact, except to some extent in January. In December and January, the negative NAO-like signal is only clearly seen in the first half of the record, whereas it is found in both halves in February and March. Whether this reflects sample limitation or true nonstationarity would be difficult to establish.

In all cases, a broad synchronous (at lag 0) SAT warming of $1^{\circ}-3^{\circ} \mathrm{C}$ is found in the regions where the sea ice decreases, which reflects the rapid thermodynamical response of the atmospheric boundary layer to the turbulent heat flux released by sea ice retreat and heat advection by the atmospheric patterns that contributed to the sea ice melting (not shown, as cause and effect are not distinguished). A weaker SAT warming is still seen near the sea ice edge at lag 1 and even lag 2, notably in the BK Seas, but these lags are dominated by a broad dynamical impact on SAT and lower-tropospheric thickness (Fig. 12). The regression maps of the two variables are similar, except that $\Delta Z$ is smoother, and they change little between months, except in February when regressed onto January dPC1, which is discussed below. There is very little field significance in the regressions at lag 1 onto November and December dPC1, except above the Canadian Archipelago (not shown), while at lag 2 and 3 a field significant warming is found in a large region centered in northeastern Canada, and some cooling over parts of Eurasia and the midlatitude oceans. As the multiple regressions indicate that some of this cooling is linked to concomitant SST or snow-cover anomalies, only multiple regressions are given. In January (Fig. 12, left), based on November dPC1, field significance is large. There is a broad warming above eastern North America, the Labrador Sea, and the
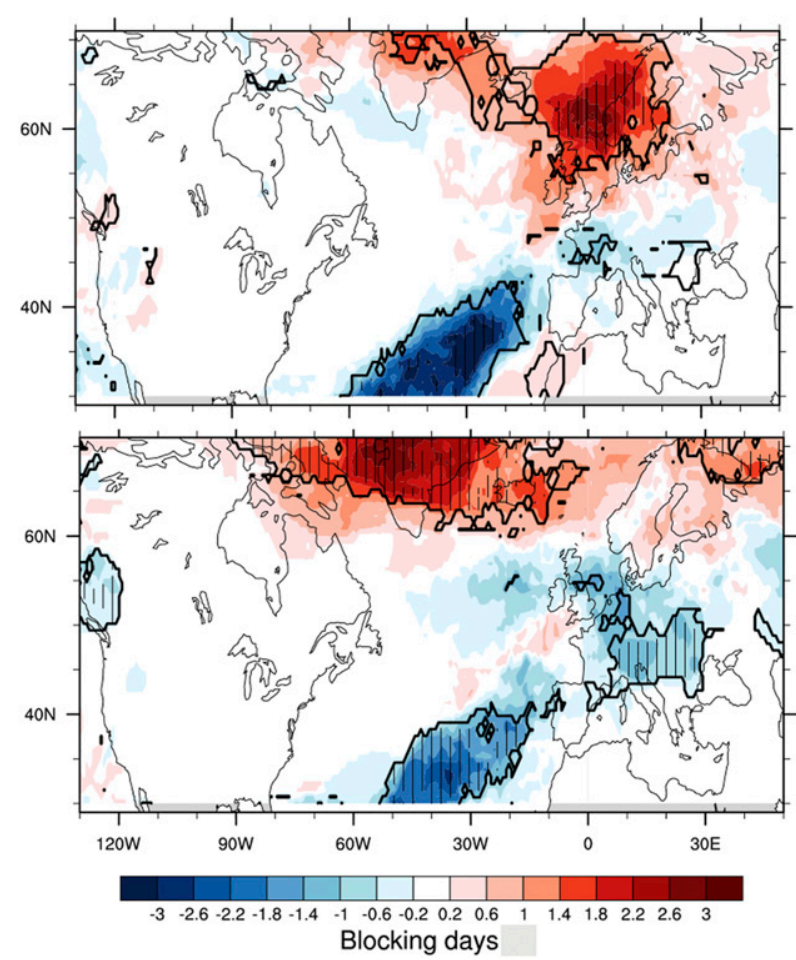

FIG. 11. Multiple regression of the number of blocking days in (top) January and (bottom) February on the SIC index in December. The contours indicate $10 \%$ significance and hatching significance based on an FDR of $10 \%$. 

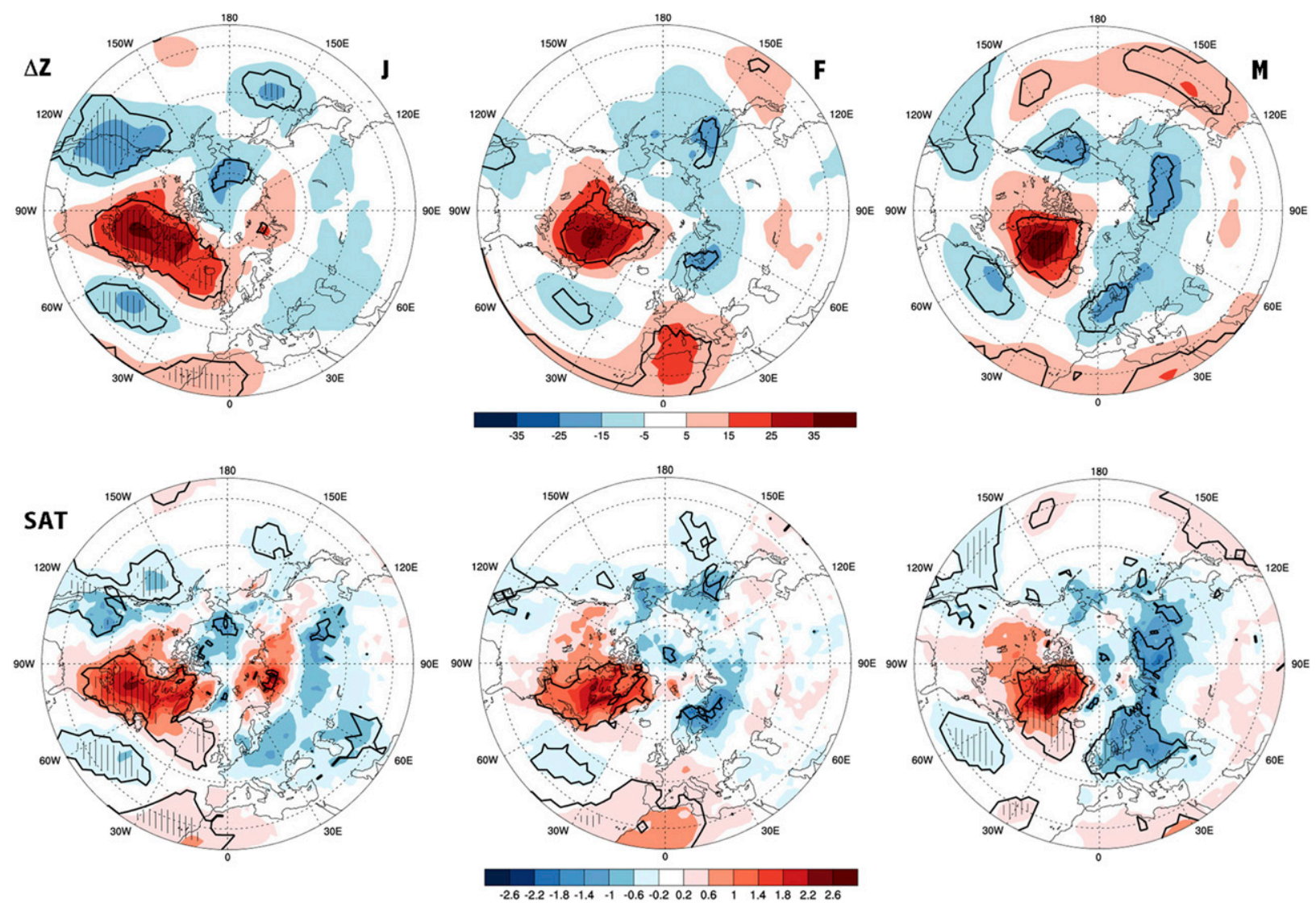

FIG. 12. Multiple regression of (top) $\Delta Z$ (m) and (bottom) SAT $\left({ }^{\circ} \mathrm{C}\right.$ ) in (left) January and (center) February on November dPC1, and (right) in March on December dPC1, based on multiple regression. The contours indicate $10 \%$ significance and hatching significance based on an FDR of $10 \%$.

subpolar North Atlantic, reaching $2^{\circ} \pm 0.8^{\circ} \mathrm{C}$ in northeastern Canada, which is about $2 / 3$ of the local detrended SAT standard deviation. There is also a weaker warming off North Africa, and significant cooling in the subtropical North Atlantic and near the North American west coast. Similar patterns are found with December regressors, but significance is much weaker. The regression maps remain broadly similar in February, but with more confined warming centered on northeastern Canada and much weaker oceanic cooling. Statistical significance is lower, whether obtained from lag 2 based on December dPC1 (not shown) or lag 3 based on November dPC1 (Fig. 12, center). Field significance is again found in March at lag 3 (right) for the broad warming near northeastern North America and the Labrador Sea, the oceanic cooling, and a cooling (highly significant in the NA-EA domain) over the northern part Europe exceeding $1^{\circ} \pm 0.6^{\circ} \mathrm{C}$. The March SAT and $\Delta Z$ patterns are similar when regressed on the January regressors, but field significance is only found in the NA-EA domain. In summary, these temperature patterns in part resemble the temperature signature of a negative NAO phase.
In addition to the negative $\mathrm{NAO}$ seen throughout the winter, the SIC fluctuations precede a different atmospheric signal, which is only found in February in the regressions onto January dPC1 at lag 1 (Fig. 13). The signal is field significant for most tropospheric variables, but very small in the stratosphere, and very similar in multiple regressions. There is a large anticyclonic signal centered on the Ural Mountains that tilts northward with height (Fig. 13) and strongly enhanced Ural blocking (Fig. 14, right). However, a blocking decrease is seen in the regression on minus the northeastern United States snow cover (Fig. 14, left), suggesting that snow cover affects Ural blocking in an opposite manner. Elsewhere, there is little correspondence between the signal at sea level and higher in the troposphere. Large field significant temperature anomalies are also found, with a broad SAT and $\Delta Z$ warming over northeastern North America, and warming over the BK Seas, and significant cooling over much of Asia. These signals show some similarity with the warm Arctic-cold Eurasia (WACE) and the Ural blocking patterns (Mori et al. 2014; Luo et al. 2016; Sun et al. 2018). Only the Ural high 

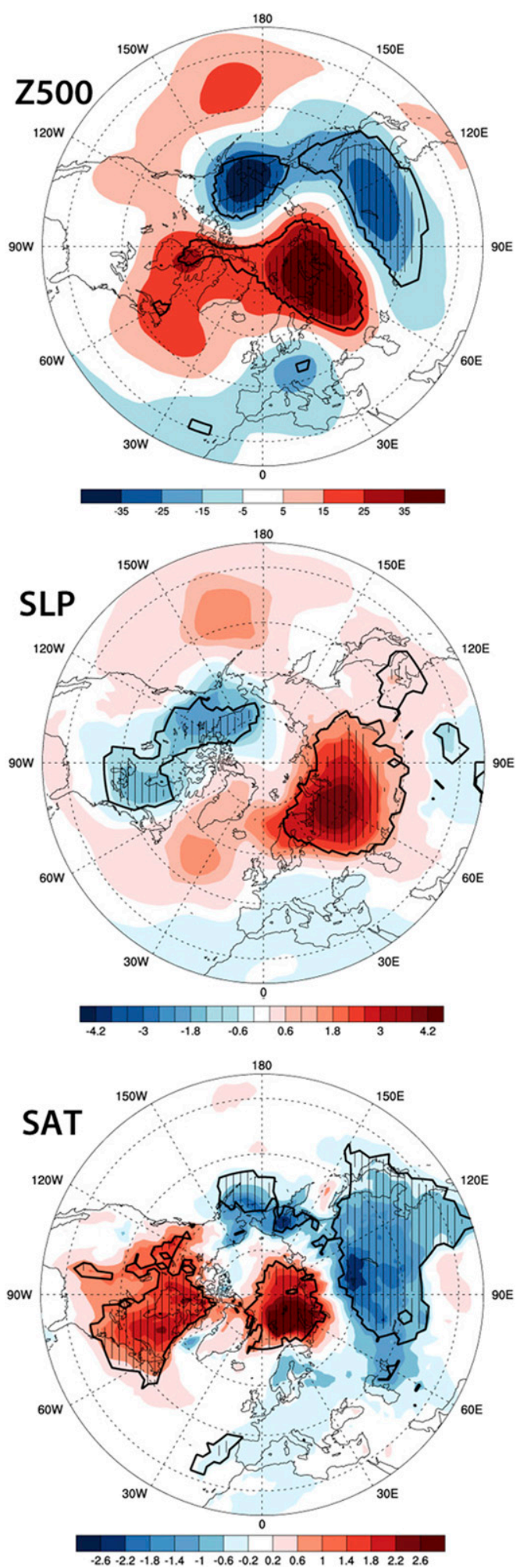

FIG. 13. Multiple regression of (top) Z500 (m), (middle) SLP $(\mathrm{hPa})$, and (bottom) SAT $\left({ }^{\circ} \mathrm{C}\right)$ anomalies in February onto dPC1 in January. The contours indicate $10 \%$ significance and hatching significance based on an FDR of $10 \%$. is found in the (otherwise dissimilar) two halves of the period (not shown). However, the February signals are not found in the regressions on November or December $\mathrm{dPC} 1$, and there is no significant relation between February dPC1 and the atmosphere in March. Hence, they lack robustness and are not considered further.

\section{Implication for direct impact of the SIC decline between 1979 and 2016}

Under the assumption that the atmosphere responds identically to slow and fast SIC changes of an identical pan-Arctic spatial pattern, section 3 may be used to estimate the direct atmospheric changes caused by the decreasing sea ice cover in the 1979-2016 period. The most robust response is the negative NAO in January, February, and, albeit weaker, in March, which lags the SIC fluctuations by about 2 months. The response in December lacks field significance. Hence, if winter is defined from December to February (DJF), the winter response is about $2 / 3$ of that found in section 3 , while is only a little smaller if winter is from January to March (JFM).

As no NAO-like response to SIC was detected during spring, summer, and fall, it is not obvious how to scale this atmospheric response to estimate that to the observed sea ice loss in the 1979-2016 period. In perpetual winter conditions, the estimated averaged rate of change per decade would be approximately given by 1 (in DJF, assuming no December response) to 1.5 (in JFM, assuming a slightly weaker March response) times the responses in section 3. This takes into account the long-term changes in the November and December PC1s during the 38 years between 1979 and 2016 (2.8, as given by the red curves in Fig. 1) and the limited amplitude of their interannual fluctuations ( $\mathrm{rms} \sim 0.45$ in both cases), yielding a January or February scaling of $2.8 /(3.8 \times 0.45)=1$.6. Such scaling yields very large rates of change of the winter conditions, for instance a warming rate of $2^{\circ}-3^{\circ} \mathrm{C}$ decade ${ }^{-1}$ for SAT in northeastern North America, and a Z500 increase of 40-60 m decade ${ }^{-1}$ over the northern North Atlantic. However, as discussed in section 5, this assumes linearity and does not take into account that there is no corresponding response during the other 9 months.

\section{Summary and discussion}

The direct response of the atmospheric circulation in the cold season to the observed Arctic sea ice loss between 1979 and 2016 was estimated by assuming that the response to the slow sea ice retreat is the same as that to interannual pan-Arctic SIC fluctuations with identical spatial patterns. The latter was estimated by lag regression, using multiple regressions for attribution since 


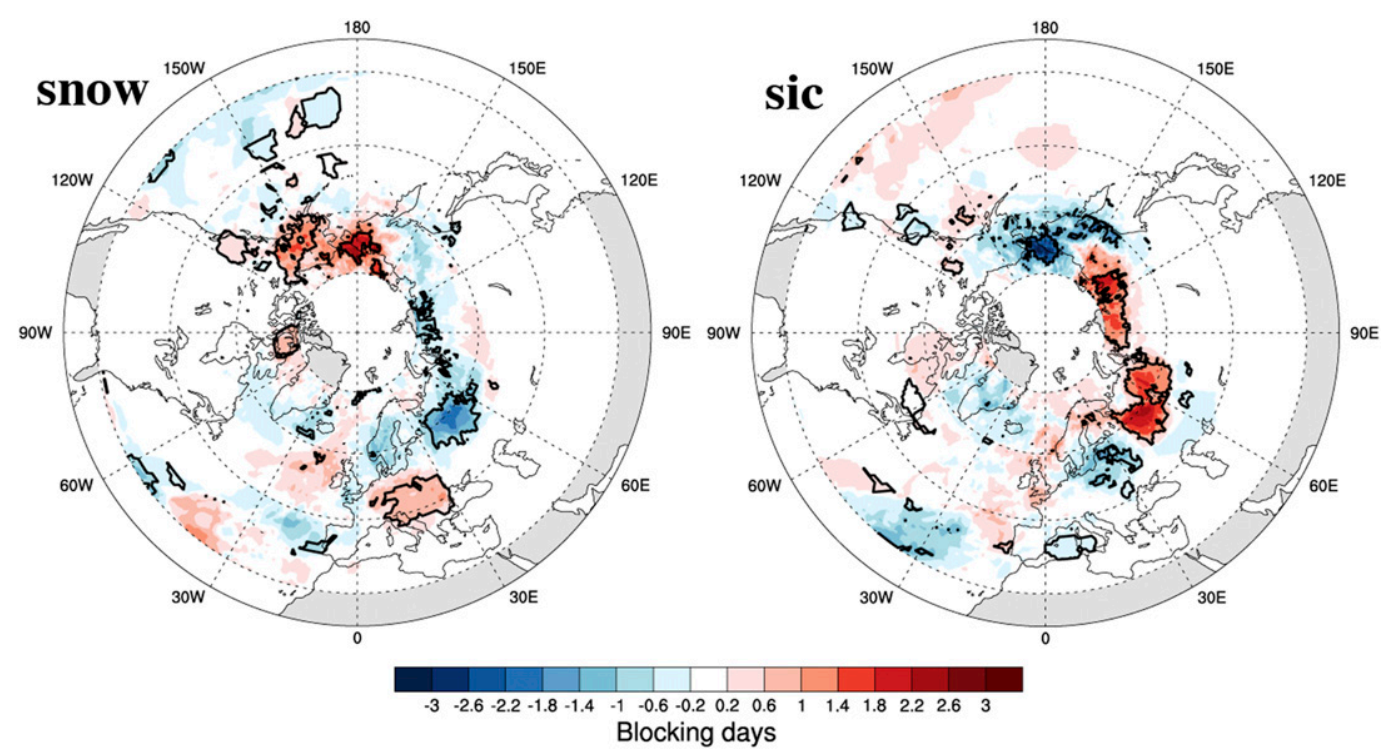

FIG. 14. Multiple regression of the number of blocking days in February onto (left) minus the eastern North America snow index and (right) SIC in January. The contours indicate $10 \%$ significance.

there were synchronous SST and snow-cover fluctuations (no significant link was found with the QBO).

No significant large-scale atmospheric response was detected in October and November. In December, a field significant negative NAO-like signal lags the November SIC fluctuations in the stratosphere, together with a negative tropospheric NAO signal that is only locally significant. However, multiple regressions show that the stratospheric signal is primarily driven by concomitant Siberian snow-cover anomalies. Numerous studies found a link between autumnal Eurasian snow cover and the winter AO via a stratospheric pathway, although its robustness has been questioned [see the review by Henderson et al. (2018)]. For instance, Gastineau et al. (2017) found that a snow-cover increase in southeastern Siberia during November preceded a negative $\mathrm{NAO} / \mathrm{AO}$ in winter via a stratospheric pathway, perhaps amplified by a SIC decrease in the BK Seas, although snow cover was the main driver. Hence, the SIC fluctuations may only drive a tropospheric NAO- signal in December, albeit too weak to be field significant.

On the other hand, the analysis shows that in January, February, and, less significantly, in March, SIC leads a robust and field significant negative NAOlike signal in the troposphere and near the tropopause, with a tropospheric high exceeding about $40 \pm 13 \mathrm{~m}$ for $\mathrm{Z} 500$ and $3.8 \pm 1.4 \mathrm{hPa}$ for SLP above Iceland. There is also a smaller SLP decrease over northeastern Canada, a southeastward shift of the westerlies over the North Atlantic, and a modulation of blocking activity, which decreases in the eastern subtropical North Atlantic in January, extending to central Europe in February while increasing over northern Europe and Greenland. As there is no field significant Z50 signal in the stratosphere, the pan-Arctic SIC loss fluctuations primarily influence the wintertime atmospheric circulation via a tropospheric pathway. Yet, the December SIC fluctuations induce in January a southward shift of the zonal wind at $50 \mathrm{hPa}$ (U50) that is (only) field significant in the NA-EA sector, so that there may be a small stratospheric response in January. Note that the stratosphere is not fully resolved in ERA-Interim and it would be interesting to repeat this analysis in other reanalyses such as ERA5 (Hersbach et al. 2019).

The atmospheric response to the SIC fluctuations generally reaches maximum amplitude in 2 months, broadly consistent with the atmospheric response time to SIC changes in Deser et al. (2007) and Frankignoul et al. (2014), and presumably reflecting the time it takes for eddy-mean flow interactions to strengthen the signal. In all months, there is a broad synchronous nearsurface warming above the sea ice retreat. When the atmosphere lags, SAT and $\Delta Z$ are dominated by dynamically driven temperature changes that induce a strong warming reaching $\sim 2^{\circ} \pm 0.8^{\circ} \mathrm{C}$ above northeastern Canada and the Labrador Sea from January to March. A northern Europe cooling of $\sim 1^{\circ} \pm 0.65^{\circ} \mathrm{C}$ in March is also attributed to SIC. The only evidence that the pan-Arctic sea ice loss fluctuation could drive the WACE pattern is obtained in February for SIC fluctuations in January, but the signal is not found for other lags or months, so that we focus on the more robust NAO-like response, which could serve as a benchmark to test climate models. 
An influence of interannual SIC fluctuations on the wintertime atmospheric circulation has been detected in many observational studies, often focusing on the autumn and winter BK SIC fluctuations. However, the latter are mostly anticorrelated with the SIC changes in the Labrador Sea [the seesaw in Strong et al. (2009) and Frankignoul et al. (2014)], unlike in the sea ice loss pattern, where the sea ice edge retreats everywhere. Because the response to pan-Arctic SIC changes may substantially differ from that to BK Seas SIC changes (Sun et al. 2015; McKenna et al. 2018; Screen 2017), a direct comparison with the present analysis is not warranted. However, we note that in these studies, a negative NAO lags a BK SIC decrease, suggesting its important role in our results. King et al. (2016) and Kug et al. (2015) suggested that an autumn sea ice retreat in the BK Seas leads to a negative AO via a stratospheric pathway, while our analysis agrees with García-Serrano and Frankignoul (2016), Kretschmer et al. (2016), and García-Serrano et al. (2017), who argued that the NAO - following a sea ice loss in the BK Seas is due to tropospheric eddy-mean flow interactions. Mori et al. (2014) argued that the sea ice reduction in the BK Seas drives the WACE pattern instead of the NAO, but their observational evidence was derived from composite differences between low-ice and high-ice years, so that, as in Mori et al. (2019), cause and effect were not distinguished, and attribution was only supported by model simulations (Blackport et al. 2019). However, synchronous boundary forcings were not considered in these studies, except in Furtado et al. (2016), Kretschmer et al. (2016), and Gastineau et al. (2017), nor was field significance considered, possibly leading to overestimated statistical significance.

If the atmosphere responds similarly to slow and fast changes of an identical pan-Arctic SIC pattern and stationarity is assumed, the direct atmospheric changes caused by the decreasing sea ice cover in the 1979-2016 period can be estimated. The most robust response to the interannual SIC fluctuations is the negative NAO in January, February, and, albeit weaker, March. The December response is smaller and lacks field significance, and no NAO-like response is found during the rest of the year. In perpetual winter conditions and if linearity could be assumed, the estimates suggest very large rates of changes, for instance a warming rate of $2^{\circ}-3^{\circ} \mathrm{C}$ decade ${ }^{-1}$ for SAT in northeastern North America and a Z500 increase of about $40-60 \mathrm{~m}$ decade $^{-1}$ over the northern North Atlantic. Note that there is much uncertainty in these amplitude estimates, as shown by their $90 \%$ confidence interval (from $0.7^{\circ}-3.3^{\circ}$ to $1^{\circ}-5^{\circ} \mathrm{C}$ decade ${ }^{-1}$ and from $20-60$ to $30-90 \mathrm{~m} \mathrm{decade}^{-1}$, respectively), as derived from their standard errors and the scaling discussed in section 4. However, such large changes would progressively alter the mean background atmospheric winter circulation, so that linearity could not be reasonably assumed (Smith et al. 2017). In addition, this does not take into account that there is no NAO-like response to the SIC fluctuations during the other 9 months of the year, or no significant cooling in northern Europe other than in March, so that the predicted yearly averaged rates of change would be at least 4 times smaller and there would only be a small averaged cooling rate over northern Europe. How to relate a signal that only occurs during winter, or part of it, to a rate of change that would not lead to increasing discontinuities should depend on the atmospheric state and influence during the other seasons. For instance, the SAT increase during one winter could be damped, advected, or diffused by the atmospheric conditions during the following spring, summer, and fall, rather than remain unaltered until the following winter. How and to what extent this occurs remains to be established.

There is no a priori reason why the direct impact of the sea ice loss should be detectable in the observed longterm trends, since it would likely be masked or compensated by other forcings, such as the changes in greenhouse gas and aerosol concentration, SST, snow cover, and by the indirect influence of SIC loss. Nonetheless, we note that our estimates of the SAT changes are larger than, but not inconsistent with, the observed rate of change in certain regions, such as northeastern North America where the DJF SAT trend is $\sim 1^{\circ} \mathrm{C}$ decade ${ }^{-1}$ from 1982 to 2014, also peaking in northeastern Canada (Ogawa et al. 2018). On the other hand, there is no observational evidence of a trend toward a more negative NAO during 1982-2014.

As summarized in section 1, several studies investigated the direct atmospheric response to sea ice loss by comparing AGCM simulations driven by climatological and perturbed SIC, but there is no consensus on their impacts on the midlatitudes, and the prescribed sea ice anomaly patterns often differed from the pan-Arctic sea ice loss pattern considered here. Our estimates should be more comparable to AMIP-type simulations with AGCMs, where the direct sea ice impact is derived from the difference between large ensemble of simulations using observed and climatological SIC in the boundary conditions, while the SST and the external forcing evolution are prescribed from observations. Perlwitz et al. (2015) found that the Arctic sea ice loss between 1979-88 and 2003-12 had a small impact during fall (OctoberDecember), warming the zonal-mean temperature in the lowermost troposphere at high latitudes, which is not inconsistent with the lack of field significant tropospheric response found here in autumn. Sun et al. (2016) found that the sea ice loss between 1990/91 and 2013/14 caused in winter (DJF) a warming trend mainly confined to the Arctic and high-latitude eastern North America, where it 
reached $1^{\circ} \mathrm{C}$ decade ${ }^{-1}$, and no continental cooling or significant SLP trend over middle and high latitudes. Mori et al. (2019, their supplementary Fig. 10a) found similar 1995-2014 warming trends for the SAT over the Arctic and, north of about $60^{\circ} \mathrm{N}$, Eurasia and eastern North America, and only a small $\left(0.5-1 \mathrm{hPa}\right.$ decade $\left.{ }^{-1}\right)$ SLP increase over Greenland. Ogawa et al. (2018), using a large ensemble of AGCM experiments with six models only found a weak dynamical response to SIC fluctuations. Therefore, none of the previous studies simulated a significant link between the Arctic sea ice loss and winter Eurasian SAT cooling, which is consistent with our most robust results. However, these AMIP-type simulations also do not reproduce the large atmospheric circulation changes suggested here. More work is needed to explore the reasons of this discrepancy, perhaps further using causal effect network (Kretschmer et al. 2016) to identify more accurately other possible missing drivers of the midlatitude atmospheric fluctuations, and to explain why AGCMs poorly represent the dynamical response to the Arctic sea ice loss. The CMIP6 PAMIP results (Smith et al. 2019) will also help to further assess the atmospheric response in models.

Acknowledgments. This research was supported by the Blue-Action project (European Union's Horizon 2020 research and innovation program, Grant 727852) and by the National Science Foundation (OPP 1736738). We thank the three reviewers for their thoughtful and constructive comments.

\section{REFERENCES}

Barnes, E. A., and J. A. Screen, 2015: The impact of Arctic warming on the midlatitude jet-stream: Can it? Has it? Will it? Wiley Interdiscip. Rev.: Climate Change, 6, 277-286, https:// doi.org/10.1002/WCC.337.

Blackmon, M. L., 1976: A climatological spectral study of the $500 \mathrm{mb}$ geopotential height of the Northern Hemisphere. J. Atmos. Sci., 33, 1607-1623, https://doi.org/10.1175/15200469(1976)033<1607:ACSSOT>2.0.CO;2.

Blackport, R., and P. J. Kushner, 2017: Isolating the atmospheric circulation response to Arctic sea ice loss in the coupled climate system. J. Climate, 30, 2163-2185, https://doi.org/ 10.1175/JCLI-D-16-0257.1.

_ J. A. Screen, K. van der Wiel, and R. Bintanja, 2019: Minimal influence of reduced Arctic sea ice on coincident cold winters in mid-latitudes. Nat. Climate Change, 9, 697-704, https:// doi.org/10.1038/s41558-019-0551-4.

Bony, S., and Coauthors, 2006: How well do we understand and evaluate climate change feedback processes? J. Climate, 19, 3445-3482, https://doi.org/10.1175/JCLI3819.1.

Bretherton, C., M. Widmann, V. Dymnikov, J. Wallace, and I. Bladé, 1999: The effective number of spatial degrees of freedom of a time-varying field. J. Climate, 12, 1990-2009, https:// doi.org/10.1175/1520-0442(1999)012<1990:TENOSD>2.0.CO;2.
Cavalieri, D., C. Parkinson, P. Gloersen, and H. J. Zwally, 1996: Sea ice concentrations from Nimbus-7 SMMR and DMSP SSM/I passive microwave data, version 1. NASA National Snow and Ice Data Center Distributed Active Archive Center, accessed 4 December 2017, https://doi.org/10.5067/8GQ8LZQVL0VL.

Cohen, J., and Coauthors, 2014: Recent Arctic amplification and extreme mid-latitude weather. Nat. Geosci., 7, 627-637, https:// doi.org/10.1038/ngeo2234.

Czaja, A., and C. Frankignoul, 2002: Observed impact of Atlantic SST anomalies on the North Atlantic Oscillation. J. Climate, 15, 606-623, https://doi.org/10.1175/1520-0442(2002)015<0606: OIOASA $>2.0 . \mathrm{CO} ; 2$.

Dee, D. P., and Coauthors, 2011: The ERA-Interim reanalysis: Configuration and performance of the data assimilation system. Quart. J. Roy. Meteor. Soc., 137, 553-597, https://doi.org/ 10.1002/qj.828.

Deser, C., R. A. Tomas, and S. Peng, 2007: The transient atmospheric circulation response to North Atlantic SST and sea ice anomalies. J. Climate, 20, 4751-4767, https://doi.org/10.1175/JCLI4278.1.

,-- , and L. Sun, 2015: The role of ocean-atmosphere coupling in the zonal-mean atmospheric response to Arctic sea ice loss. J. Climate, 28, 2168-2186, https://doi.org/10.1175/JCLID-14-00325.1.

Ding, Q., J. M. Wallace, D. S. Battisti, E. J. Steig, A. J. E. Galland, H.-J. Kim, and L. Geng, 2014: Tropical forcing of the recent rapid Arctic warming in northeastern Canada and Greenland. Nature, 509, 209-212, https://doi.org/10.1038/nature13260.

Flournoy, M. D., S. B. Feldstein, S. Lee, and E. E. Clothiaux, 2016: Exploring the tropically excited Arctic warming mechanism with station data: Links between tropical convection and Arctic downward infrared radiation. J. Atmos. Sci., 73, 1143 1158, https://doi.org/10.1175/JAS-D-14-0271.1.

Francis, J. A., and S. J. Vavrus, 2012: Evidence linking Arctic amplification to extreme weather in mid-latitudes. Geophys. Res. Lett., 39, L06801, https://doi.org/10.1029/2012GL051000.

— W. Chan, D. J. Leathers, J. R. Miller, and D. E. Veron, 2009: Winter Northern Hemisphere weather patterns remember summer Arctic sea-ice extent. Geophys. Res. Lett., 36, L07503, https://doi.org/10.1029/2009GL037274.

Frankignoul, C., N. Sennéchael, and P. Cauchy, 2014: Observed atmospheric response to cold season sea ice variability in the Arctic. J. Climate, 27, 1243-1254, https://doi.org/10.1175/ JCLI-D-13-00189.1.

— G. Gastineau, and Y.-O. Kwon, 2017: Estimation of the SST response to anthropogenic and external forcing, and its impact on the Atlantic multidecadal oscillation and the Pacific decadal oscillation. J. Climate, 30, 9871-9895, https://doi.org/ 10.1175/JCLI-D-17-0009.1.

Furtado, J. C., J. L. Cohen, and E. Tziperman, 2016: The combined influences of autumnal snow and sea ice on Northern Hemisphere winters. Geophys. Res. Lett., 43, 3478-3485, https://doi.org/10.1002/2016GL068108.

García-Serrano, J., and C. Frankignoul, 2016: On the feedback of the winter NAO-driven sea ice anomalies. Climate Dyn., 47, 1601-1612, https://doi.org/10.1007/s00382-015-2922-5.

— - _ G. Gastineau, and A. de la Cámara, 2015: On the predictability of the winter Euro-Atlantic climate: Lagged influence of autumn Arctic sea ice. J. Climate, 28, 5195-5216, https://doi.org/10.1175/JCLI-D-14-00472.1.

_ _ and Coauthors, 2017: Multi-model assessment of linkages between eastern Arctic sea-ice variability and the Euro-Atlantic atmospheric circulation in current climate. Climate Dyn., 49 , 2407-2429, https://doi.org/10.1007/s00382-016-3454-3. 
Gastineau, G., J. García-Serrano, and C. Frankignoul, 2017: The influence of autumnal Eurasian snow cover on climate and its links with Arctic sea ice cover. J. Climate, 30, 7599-7619, https://doi.org/10.1175/JCLI-D-16-0623.1.

Handorf, D., R. Jaiser, K. Dethloff, A. Rinke, and J. Cohen, 2015: Impacts of Arctic sea ice and continental snow cover changes on atmospheric winter teleconnections. Geophys. Res. Lett., 42, 2367-2377, https://doi.org/10.1002/2015GL063203.

Hardiman, S. C., N. Butchart, S. M. Osprey, L. J. Gray, A. C. Bushell, and T. J. Hinton, 2010: The climatology of the middle atmosphere in a vertically extended version of the Met Office's climate model. Part I: Mean state. J. Atmos. Sci., 67, 1509-1525, https://doi.org/10.1175/2009JAS3337.1.

Henderson, G. R., Y. Peings, J. C. Furtado, and P. J. Kushner, 2018 : Snow-atmosphere coupling in the Northern Hemisphere. Nat. Climate Change, 8, 954-963, https://doi.org/10.1038/s41558018-0295-6.

Hersbach, H., and Coauthors, 2019: Global reanalysis: Goodbye ERA-Interim, hello ERA5. ECMWF Newsletter, No. 159, ECMWF, Reading, United Kingdom, 17-24, https://doi.org/ 10.21957/vf291hehd7.

Jaiser, R., K. Dethloff, D. Handorf, A. Rinke, and J. Cohen, 2012: Impact of sea ice cover changes on the Northern Hemisphere atmospheric winter circulation. Tellus, 64A, 11595, https:// doi.org/10.3402/tellusa.v64i0.11595.

Judge, G. G., R. C. Hill, W. E. Griffiths, H. Lütkepohl, and T.-C. Lee, 1988: Introduction to the Theory and Practice of Econometrics. 2nd ed. John Wiley and Sons, $1056 \mathrm{pp}$.

Kendall, M. G., 1946: The Advanced Theory of Statistics. Charles Griffin and Co., 521 pp.

Kidston, J., A. A. Scaife, S. C. Hardiman, D. M. Mitchell, N. Butchart, M. P. Baldwin, and L. J. Gray, 2015: Stratospheric influence on tropospheric jet streams, storm tracks and surface weather. Nat. Geosci., 8, 433-440, https://doi.org/10.1038/ngeo2424.

Kim, B.-M., S.-W. Son, S.-K. Min, J.-H. Jeong, S.-J. Kim, X. Zhang, T. Shim, and J.-H. Yoon, 2014: Weakening of the stratospheric polar vortex by Arctic sea-ice loss. Nat. Commun., 5, 4646, https://doi.org/10.1038/NCOMMS5646.

King, M. P., M. Hell, and N. Keenlyside, 2016: Investigation of the atmospheric mechanisms related to the autumn sea ice and winter circulation link in the Northern Hemisphere. Climate Dyn., 46, 1185-1195, https://doi.org/10.1007/s00382-015-2639-5.

- I. Herceg-Bulić, I. Bladé, J. García-Serrano, N. Keenlyside, F. Kucharski, C. Li, and S. Sobolowski, 2018: Importance of late fall ENSO teleconnection in the Euro-Atlantic sector. Bull. Amer. Meteor. Soc., 99, 1337-1343, https://doi.org/ 10.1175/BAMS-D-17-0020.1.

Kolstad, E. W., and J. A. Screen, 2019: Non-stationary relationship between autumn Arctic sea ice and the winter North Atlantic Oscillation. Geophys. Res. Lett., 46, 7583-7591, https://doi.org/ 10.1029/2019GL083059.

Kretschmer, M., D. Coumou, J. F. Donges, and J. Runge, 2016: Using causal effect networks to analyze different Arctic drivers of midlatitude winter circulation. J. Climate, 29, 40694081, https://doi.org/10.1175/JCLI-D-15-0654.1.

Kug, J. S., J. H. Jeong, Y. S. Jang, B. M. Kim, C. K. Folland, S. K Min, and S. W. Son, 2015: Two distinct influences of Arctic warming on cold winters over North America and East Asia. Nat. Geosci., 8, 759-762, https://doi.org/10.1038/ ngeo2517.

Kwon, Y.-O., A. Camacho, C. Martinez, and H. Seo, 2018: North Atlantic winter eddy-driven jet and atmospheric blocking variability in the Community Earth System Model version 1
Large Ensemble simulations. Climate Dyn., 51, 3275-3289, https://doi.org/10.1007/s00382-018-4078-6.

Liu, J. P., J. A. Curry, H. Wang, M. Song, and R. M. Horton, 2012: Impact of declining Arctic sea ice on winter snowfall. Proc. Natl. Acad. Sci. USA, 109, 4074-4079, https://doi.org/10.1073/ pnas.1114910109; Corrigendum, 109, 6781-6783, https://doi.org/ 10.1073/pnas.1204582109.

_, M. Song, R. M. Horton, and Y. Hu, 2013: Reducing spread in climate model projection of a September ice-free Arctic. Proc. Natl. Acad. Sci. USA, 110, 12571-12576, https://doi.org/ 10.1073/pnas.1219716110.

Luo, D., Y. Xiao, Y. Yao, A. Dai, I. Simmonds, and C. Franzke, 2016: Impact of Ural blocking on winter warm Arctic-cold Eurasian anomalies. Part I: Blocking-induced amplification. J. Climate, 29, 3925-3947, https://doi.org/10.1175/JCLI-D-15-0611.1.

McCusker, K. E., J. C. Fyfe, and M. Sigmond, 2016: Twenty-five winters of unexpected Eurasian cooling unlikely due to Arctic sea-ice loss. Nat. Geosci., 9, 838-842, https://doi.org/10.1038/ ngeo2820.

, J. C. Kushner, J. C. Fyfe, M. Sigmond, V. V. Kharin, and C. M. Bitz, 2017: Remarkable separability of circulation response to Arctic sea ice loss and greenhouse gas forcing. Geophys. Res. Lett., 44, 7955-7964, https://doi.org/10.1002/2017GL074327.

McKenna, C. M., T. J. Bracegirdle, E. F. Shuckburgh, P. H. Haynes, and M. M. Joshi, 2018: Arctic sea ice loss in different regions leads to contrasting Northern Hemisphere impacts. Geophys. Res. Lett., 45, 945-954, https://doi.org/10.1002/ 2017GL076433.

Mori, M., M. Watanabe, H. Shiogama, J. Inoue, and M. Kimoto, 2014: Robust Arctic sea-ice influence on the frequent Eurasian cold winters in past decades. Nat. Geosci., 7, 869-873, https:// doi.org/10.1038/ngeo2277.

-, Y. Kosaka, M. Watanabe, H. Nakamura, and M. Kimoto, 2019: A reconciled estimate of the influence of Arctic sea-ice loss on recent Eurasian cooling. Nat. Climate Change, 9, 123 129, https://doi.org/10.1038/s41558-018-0379-3.

Nakamura, T., K. Yamazaki, K. Iwamoto, M. Honda, Y. Miyoshi, Y. Ogawa, and J. Ukita, 2015: A negative phase shift of the winter $\mathrm{AO} / \mathrm{NAO}$ due to the recent Arctic sea-ice reduction in late autumn. J. Geophys. Res. Atmos., 120, 3209-3227, https:// doi.org/10.1002/2014JD022848.

Naujokat, B., 1986: An update of the observed quasi-biennial oscillation of the stratospheric winds over the tropics. J. Atmos. Sci., 43, 1873-1877, https://doi.org/10.1175/1520-0469(1986) 043<1873:AUOTOQ > 2.0.CO;2.

Ogawa, F., and Coauthors, 2018: Evaluating impacts of recent Arctic sea ice loss on the Northern Hemisphere winter climate change. Geophys. Res. Lett., 45, 3255-3263, https://doi.org/ 10.1002/2017GL076502.

Oudar, T., E. Sanchez-Gomez, F. Chauvin, J. Cattiaux, L. Terray, and C. Cassou, 2017: Respective roles of direct GHG radiative forcing and induced Arctic sea ice loss on the Northern Hemisphere atmospheric circulation. Climate Dyn., 49, 36933713, https://doi.org/10.1007/s00382-017-3541-0.

Pedersen, R., I. Cvijanovic, P. Langen, and B. Vinther, 2016: The impact of regional Arctic sea ice loss on atmospheric circulation and the NAO. J. Climate, 29, 889-902, https://doi.org/ 10.1175/JCLI-D-15-0315.1.

Peings, Y., 2019: Ural blocking as a driver of early-winter stratospheric warmings. Geophys. Res. Lett., 46, 5460-5468, https:// doi.org/10.1029/2019GL082097.

- and G. Magnusdottir, 2014: Response of the wintertime Northern Hemispheric atmospheric circulation to current and projected 
Arctic sea ice decline: A numerical study with CAM5. J. Climate, 27, 244-264, https://doi.org/10.1175/JCLI-D-13-00272.1.

- H. Houville, J. Colin, D. Saint Martin, and G. Magnusdottir, 2017: Snow-(N)AO teleconnections and its modulation by the quasi-biennial oscillation. J. Climate, 30, 10 211-10 235, https:// doi.org/10.1175/JCLI-D-17-0041.1.

Perlwitz, J., M. Hoerling, and R. Dole, 2015: Arctic tropospheric warming: Causes and linkages to lower latitudes. J. Climate, 28, 2154-2167, https://doi.org/10.1175/JCLI-D-14-00095.1.

Petoukhov, V., and V. A. Semenov, 2010: A link between reduced Barents-Kara sea ice and cold winter extremes over northern continents. J. Geophys. Res., 115, D21111, https://doi.org/ 10.1029/2009JD013568.

Rayner, N. A., D. E. Parker, E. B. Horton, C. K. Folland, L. V. Alexander, D. P. Rowell, E. C. Kent, and A. Kaplan, 2003: Global analyses of sea surface temperature, sea ice, and night marine air temperature since the late nineteenth century. J. Geophys. Res., 108, 4407, https://doi.org/10.1029/2002JD002670.

Richter-Menge, J., and J. T. Mathis, Eds., 2017: The Arctic [in "State of the Climate in 2016"]. Bull. Amer. Meteor. Soc., 98 (8), S93S128, https://10.1175/2017BAMSStateoftheClimate.1.

Robinson, D. A., T. W. Estilow, and NOAA CDR Program, 2012: NOAA Climate Data Record (CDR) of Northern Hemisphere (NH) Snow Cover Extent (SCE), version 1. NOAA National Centers for Environmental Information, accessed July 2018, https://doi.org/10.7289/V5N014G9.

Ronalds, B., E. Barnes, and P. Hassanzadeh, 2018: A barotropic mechanism for the response of jet stream variability to Arctic amplification and sea ice loss. J. Climate, 31, 7069-7085, https://doi.org/10.1175/JCLI-D-17-0778.1.

Scherrer, S., M. Croci-Maspoli, C. Schwierz, and C. Appenzeller, 2006: Two dimensional indices of atmospheric blocking and their statistical relationship with winter climate patterns in the Euro-Atlantic region. Int. J. Climatol., 26, 233-249, https:// doi.org/10.1002/joc. 1250 .

Screen, J. A., 2017: Simulated atmospheric response to regional and pan-Arctic sea ice loss. J. Climate, 30, 3945-3962, https:// doi.org/10.1175/JCLI-D-16-0197.1.

— , and I. Simmonds, 2013: Exploring links between Arctic amplification and mid-latitude weather. Geophys. Res. Lett., 40, 959-964, https://doi.org/10.1002/grl.50174.

, C. Deser, I. Simmonds, and R. Tomas, 2014: Atmospheric impacts of Arctic sea-ice loss, 1979-2009: Separating forced change from atmospheric internal variability. Climate Dyn., 43, 333-344, https://doi.org/10.1007/s00382-013-1830-9.

- , and Coauthors, 2018: Consistency and discrepancy in the atmospheric response to Arctic sea-ice loss across climate models. Nat. Geosci., 11, 155-163, https://doi.org/10.1038/s41561-018-0059-y.

Shaw, T. A., J. Perlwitz, and N. Harnik, 2010: Downward wave coupling between the stratosphere and troposphere: The importance of meridional wave guiding and comparison with zonalmean coupling. J. Climate, 23, 6365-6381, https://doi.org/10.1175/ 2010JCLI3804.1.

Smith, D. M., N. J. Dunstone, A. A. Scaife, E. K. Fiedler, D. Copsey, and S. C. Hardiman, 2017: Atmospheric response to Arctic and Antarctic sea ice: The importance of oceanatmosphere coupling and the background state. J. Climate, $\mathbf{3 0}$, 4547-4565, https://doi.org/10.1175/JCLI-D-16-0564.1.
— , and Coauthors, 2019: The Polar Amplification Model Intercomparison Project (PAMIP) contribution to CMIP6: Investigating the causes and consequences of polar amplification. Geosci. Model Dev., 12, 1139-1164, https://doi.org/ 10.5194/gmd-12-1139-2019.

Strong, C., G. Magnusdottir, and H. Stern, 2009: Observed feedback between winter sea ice and the North Atlantic Oscillation. J. Climate, 22, 6021-6032, https://doi.org/10.1175/2009JCLI3100.1.

Sun, L., C. Deser, and R. A. Tomas, 2015: Mechanisms of stratospheric and tropospheric circulation response to projected Arctic sea ice loss. J. Climate, 28, 7824-7845, https://doi.org/ 10.1175/JCLI-D-15-0169.1.

_ J. Perlwitz, and M. Hoerling, 2016: What caused the recent "warm Arctic, cold continents" trend pattern in winter temperatures? Geophys. Res. Lett., 43, 5345-5352, https://doi.org/ 10.1002/2016GL069024.

- M. Alexander, and C. Deser, 2018: Evolution of the coupled climate response to Arctic sea ice loss during 1990-2090 and its contribution to climate change. J. Climate, 31, 7823-7843, https://doi.org/10.1175/JCLI-D-18-0134.1.

Tang, Q., X. Zhang, X. Yang, and J. A. Francis, 2013: Cold winter extremes in northern continents linked to Arctic sea ice loss. Environ. Res. Lett., 8, 014036, https://doi.org/10.1088/17489326/8/1/014036.

Taylor, P. C., B. H. Hegyi, R. C. Boeke, and L. N. Boisvert, 2018: On the increasing importance of air-sea exchanges in a thawing Arctic: A review. Atmosphere, 9, 41, https://doi.org/ 10.3390/atmos9020041.

Vavrus, S. J., F. Wang, J. E. Martin, J. A. Francis, Y. Peings, and J. Cattiaux, 2017: Changes in North American atmospheric circulation and extreme weather: Influence of Arctic amplification and Northern Hemisphere snow cover. J. Climate, 30, 4317-4333, https://doi.org/10.1175/JCLI-D-16-0762.1.

von Storch, H., and F. W. Zwiers, 2001: Statistical Analysis in Climate Research. Cambridge University Press, $484 \mathrm{pp}$.

Wallace, J. M., I. M. Held, D. W. Thompson, K. E. Trenberth, and J. E. Walsh, 2014: Global warming and winter weather. Science, 343, 729-730, https://doi.org/10.1126/science.343.6172.729.

Walsh, J. E., 2014: Intensified warming of the Arctic: Causes and impacts on middle latitudes. Global Planet. Change, 117, 5263, https://doi.org/10.1016/j.gloplacha.2014.03.003.

Wilks, D. S., 2016: "The stippling shows statistically significant grid points": How research results are routinely overstated and overinterpreted, and what to do about it. Bull. Amer. Meteor. Soc., 97, 2263-2273, https://doi.org/10.1175/BAMS-D-15-00267.1.

Woollings, T., and Coauthors, 2018: Daily to decadal modulation of jet variability. J. Climate, 31, 1297-1314, https://doi.org/ 10.1175/JCLI-D-17-0286.1.

Wu, Q., and X. Zhang, 2010: Observed forcing-feedback processes between Northern Hemisphere atmospheric circulation and Arctic ice coverage. J. Geophys. Res., 115, D14119, https:// doi.org/10.1029/2009JD013574.

Yang, X. Y., X. Yuan, and M. Ting, 2016: Dynamical link between the Barents-Kara sea ice and the Arctic Oscillation. J. Climate, 29, 5103-5122, https://doi.org/10.1175/JCLI-D-15-0669.1.

Zhang, P., Y. Wu, I. R. Simpson, K. L. Smith, X. Zhang, B. De, and P. Callaghan, 2018: A stratospheric pathway linking a colder Siberia to Barents-Kara Sea sea ice loss. Sci. $A d v$., 4, eaat6025, https://doi.org/10.1126/SCIADV.AAT6025. 